\title{
Gender wage gap in China: a large meta-analysis
}

\author{
Ichiro Iwasaki ${ }^{1 *}$ (D) and Xinxin $\mathrm{Ma}^{2}$
}

\begin{abstract}
This paper performs a meta-analysis of 1472 estimates extracted from 199 previous studies to investigate the gender wage gap in China. The results show that, although the gender wage gap in China during the transition period has an impact that statistically significant and economically meaningful, it remains at a low level. It is also revealed that the wage gap between men and women is more severe in rural regions and the private sector than those in urban regions and the public sector. Furthermore, we found that, in China, the gender wage gap has been increasing rapidly in recent years.
\end{abstract}

Keywords: Gender wage gap, Meta-synthesis, Meta-regression analysis, Publication selection bias, China JEL classification: D63, J31, J71, P25, P36

\section{Introduction}

The modern world faces serious inequality issues. China is no exception (Knight and Song 1991; Li et al. 2017). As pointed out by the human capital theory of Becker (1964) and Mincer (1974), people are ready to understand and tolerate the existence of income inequality if it results from differentials in personal capability and/or efforts. However, if income inequality is due to highly unreasonable causes, for example discrimination, the inequality is likely to cause anger. In this sense, the gender wage gap, as suggested by the employer prejudice hypothesis (Becker 1957), is likely to serve as a hotbed of social dissatisfaction. ${ }^{1}$ It is, however, difficult to measure such unreasonable economic disparities through a simple comparison of male-female wage levels. Thus, economists conduct various econometric analyses aimed at testing whether a gender wage gap exists after controlling for a number of individual characteristics such as educational attainment, work experience, skill level, and health status, as well as employment conditions such as job types, industry sectors, and work locations. As a result, today we are able

\footnotetext{
*Correspondence: iiwasaki@ier.hit-u.ac.jp

${ }^{1}$ Institute of Economic Research, Hitotsubashi University, Naka 2-1, Kunitachi, Tokyo 186-8603, Japan

Full list of author information is available at the end of the article
}

to refer to significant empirical evidence for developed countries (de la Sara et al. 2008; Blau and Khan 2017; Hara 2018), developing countries (Ahmed and McGillivray 2015; Hallward-Driemeier et al. 2017; Deshpande et al. 2018), and former socialist transition countries (Brainerd 2000; Majchrowska and Strawiński 2018).

From the above perspectives, numerous researchers have attempted to investigate wage inequality in China focusing on the gender aspect (Meng 1998b; Gustafsson and Li 2000; Liu et al. 2000; Maurer-Fazio and Hughes 2002; Rozelle et al. 2002; Shu et al. 2007; Song et al. 2011; Ren and Miller 2012; Ma 2018a; Sun and Hung 2018; Hare 2019; Zhao et al. 2019). This may be caused by the fact that, since 1978, when the planned economic period ended, income inequality including wage gap in China has increased remarkably as the transition to a market economy has progressed. It is considered that the increase of income inequality may contribute to the growth of the gender wage gap. In addition, most other previous studies also have provided estimates of the effects of gender as one wage determinant.

\footnotetext{
$\overline{1}$ The employer prejudice hypothesis argues that, even if women and men are completely equal in terms of human capital, prejudice by employers, male employees, customers, and others leading to discriminatory treatment of women would result in gender wage disparities disadvantageous to women.
}

Springer Open

(c) The Author(s) 2020. This article is licensed under a Creative Commons Attribution 4.0 International License, which permits use, sharing, adaptation, distribution and reproduction in any medium or format, as long as you give appropriate credit to the original author(s) and the source, provide a link to the Creative Commons licence, and indicate if changes were made. The images or other third party material in this article are included in the article's Creative Commons licence, unless indicated otherwise in a credit line to the material. If material is not included in the article's Creative Commons licence and your intended use is not permitted by statutory regulation or exceeds the permitted use, you will need to obtain permission directly from the copyright holder. To view a copy of this licence, visit http://creativeco mmons.org/licenses/by/4.0/. 
Table 1 Descriptive statistics of the partial correlation coefficients, $t$ test and Shapiro-Wilk normality test of collected estimates

\begin{tabular}{|c|c|c|c|c|c|c|c|c|c|c|}
\hline & $K$ & Mean & Median & S.D & Max & Min & Kurtosis & Skewness & $t$ test & $\begin{array}{l}\text { Shapiro-Wilk } \\
\text { normality test } \\
\text { (z) }\end{array}$ \\
\hline All studies $\left(\right.$ Hypothesis $\mathrm{H}_{1}$ ) & 1472 & -0.123 & -0.115 & 0.094 & 0.392 & -0.826 & 10.193 & -0.543 & $-50.160^{* * *}$ & $10.717^{\dagger+\dagger}$ \\
\hline \multicolumn{11}{|l|}{ Target region (Hypothesis $\mathrm{H}_{2}$ ) } \\
\hline Urban region & 919 & -0.114 & -0.108 & 0.084 & 0.392 & -0.589 & 9.292 & 0.348 & $-40.962^{* * *}$ & $9.116^{t+t}$ \\
\hline Rural region & 135 & -0.184 & -0.169 & 0.124 & -0.014 & -0.826 & 8.887 & -1.798 & $-17.247^{* * *}$ & $5.918^{t+t}$ \\
\hline Region unspecified & 418 & -0.124 & -0.115 & 0.097 & 0.271 & -0.739 & 8.325 & -0.452 & $-26.209^{* * *}$ & $6.800^{t+\dagger}$ \\
\hline \multicolumn{11}{|c|}{ Target corporate sector (Hypothesis $\mathrm{H}_{3}$ ) } \\
\hline Public sector & 24 & -0.095 & -0.086 & 0.053 & 0.047 & -0.195 & 3.512 & 0.303 & $-8.771^{* * *}$ & 0.770 \\
\hline Private sector & 34 & -0.125 & -0.117 & 0.086 & 0.088 & -0.408 & 5.661 & -0.418 & $-8.415^{* * *}$ & $1.967^{\dagger \dagger}$ \\
\hline Corporate sector unspecified & 1414 & -0.123 & -0.116 & 0.095 & 0.392 & -0.826 & 10.199 & -0.536 & $-48.978^{* * *}$ & $10.634^{t+\dagger}$ \\
\hline \multicolumn{11}{|l|}{ Target period (Hypothesis $\mathrm{H}_{4}$ ) } \\
\hline 1990s or before & 315 & -0.110 & -0.097 & 0.083 & 0.088 & -0.671 & 10.421 & -1.844 & $-23.484^{* * *}$ & $7.849^{t+\dagger}$ \\
\hline $2000 s$ & 689 & -0.112 & -0.107 & 0.086 & 0.392 & -0.826 & 20.610 & -1.006 & $-34.162^{* * *}$ & $10.868^{t+\dagger}$ \\
\hline 2010 s & 468 & -0.148 & -0.153 & 0.107 & 0.271 & -0.561 & 4.507 & 0.457 & $-29.941^{* * *}$ & $5.420^{t+\dagger}$ \\
\hline
\end{tabular}

***Denotes that null hypothesis that mean is zero is rejected at the $1 \%$ level

$\mathrm{t+t}$ and $+\mathrm{t}$ denote that null hypothesis of normal distribution is rejected at the 1 and $5 \%$ levels, respectively

However, taking an overview of these research results, some unresolved issues emerge: First, as we will report later in referring to Table 1 and Fig. 1, although the vast majority of the extant literature suggests that the gender wage gap, by which the wage level is disadvantageous to women, does exist in China, contrary results have also been reported. Second, although labor market segmentation by the Hukou (population registration) system is a major issue in the Chinese economy, research on wages in China strongly tends to limit the subject of analysis to either urban regions or rural regions (Ma and Iwasaki 2020). As a result, gender wage gap differences between urban and rural regions are not sufficiently investigated. Third, a similar issue can be applied to gender wage gap differences between stateowned enterprises (SOEs) and privately-owned enterprises (POEs) as well. Fourth, since, due to restrictions in available data, the overwhelming majority of the published literature employs empirical analysis based on a cross-section data at either a single point or a number of points in time, few cases consider the dynamics of the gender wage gap from a long-term perspective. Accordingly, even though we can ascertain an unreasonable gender wage gap, which can serve as the soil of dissatisfaction in society and is an extremely important research issue not only for developed countries that are facing severe issues of inequality as well as China, which needs to secure the political and social stability of market-oriented reforms and economic growth, the disparities of the gender wage gap among regions and corporate sectors and dynamic time-series changes have been not analyzed in the majority of previous works regarding wage determinants in China.
A meta-analysis enabling the synthesis and comparison of empirical results reported in the extant literature can make it possible to obtain findings regarding issues and problems that are difficult to examine in just one study through standard empirical analysis. In this paper, we perform a large-scale meta-analysis to measure the gender wage gap in China, comprehending not only the empirical works of this subject but also a wide range of other Chinese wage studies concerning disparities of the gender wage gap among different regions and corporate sectors as well as changes over time, presenting "reviewgenerated evidence" (Nakagawa et al. 2017). Furthermore, we also test publication selection bias and examine the presence of genuine empirical evidence of the wage effect of gender in the literature as a unique mission of metaanalysis. Other examples of meta-analysis of the gender wage gap include Stanley and Jarrell (1998), Jarrell and Stanley (2004), and Weichselbaumer and Winter-Ebmer (2005); however, each of these is an international comparison focused chiefly on developed countries. What's more, they were published at least 10 years ago. In addition, to the best of our knowledge, this is the first meta-analysis in the world on the gender wage gap in China. Therefore, this paper contributes to the literature of Chinese economic studies and meta-analysis of the gender wage gap. ${ }^{2}$

\footnotetext{
2 There are several attempts to investigate the Chinese economy through meta-analysis of the existing literature. As these representative works, see Ljungwall and Tingvall (2015), Churchill and Mishra (2018), Fan et al. (2020), Ma and Iwasaki (2020) and Iwasaki et al. (2020).
} 


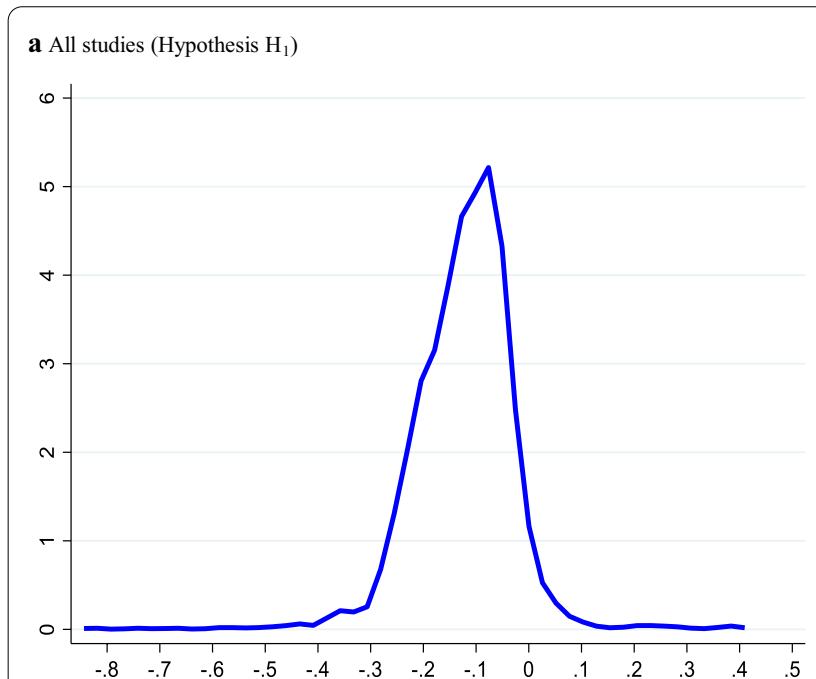

b Target region (Hypothesis $\mathrm{H}_{2}$ )

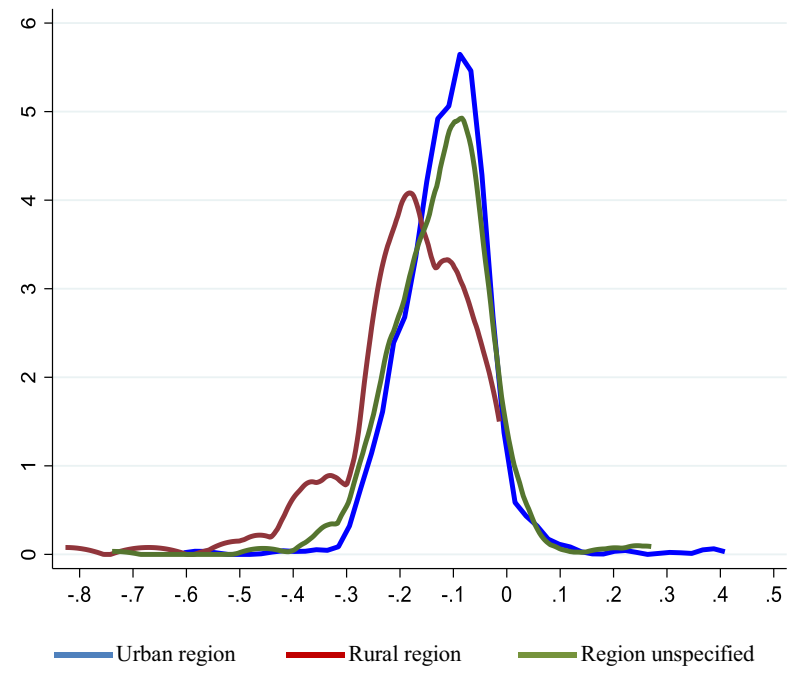

d Target period (Hypothesis $\mathrm{H}_{4}$ )

c Target corporate sector (Hypothesis $\mathrm{H}_{3}$ )
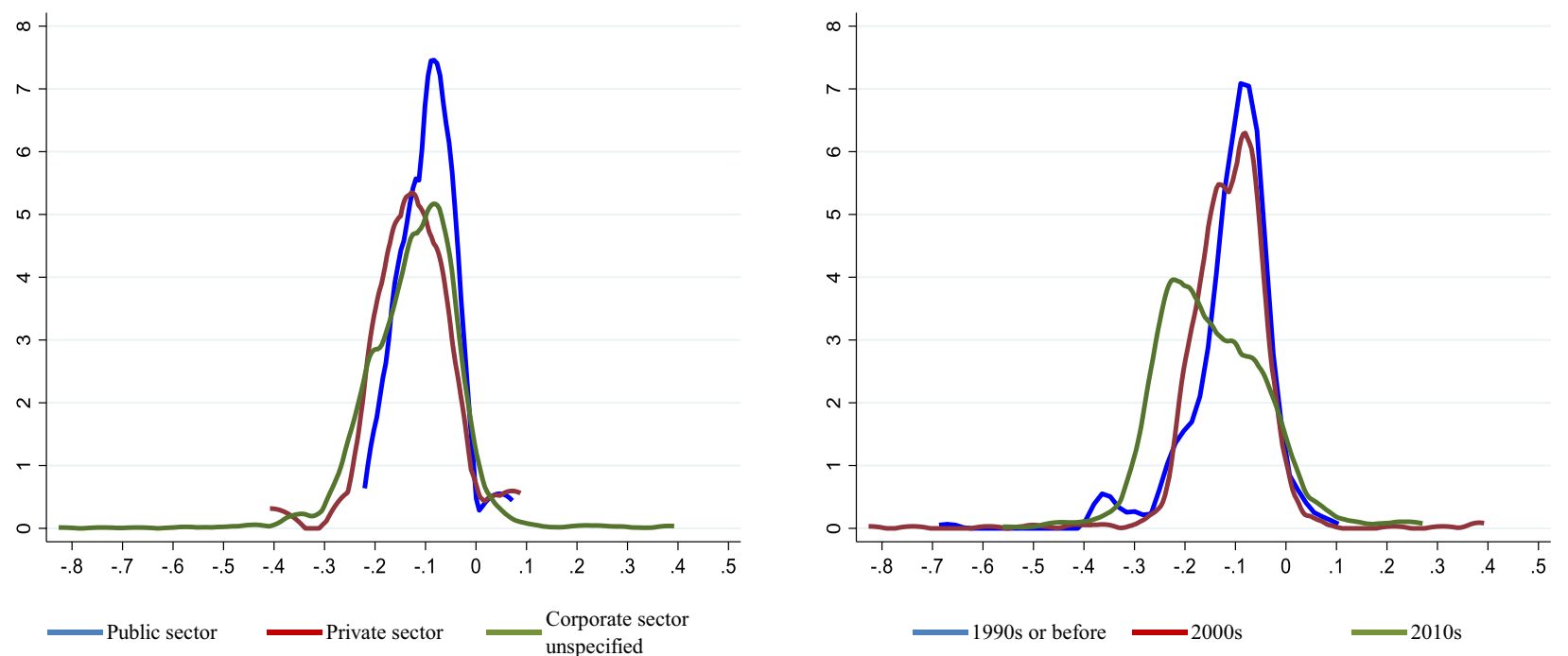

Fig. 1 Kernel density estimation of collected estimates. The vertical axis is the kernel density. The horizontal axis is the variable value. Source: See Table 1 for the number of observations and descriptive statistics

The results of meta-analysis using 1472 estimates extracted from 199 previous studies show that, although the gender wage gap in China during the transition period $^{3}$ has an impact that statistically significant and economically meaningful, it remains at a low level. It is also revealed that the wage gap between men and women

\footnotetext{
${ }^{3}$ The period from 1978 to the present is called as "the transition period" in most literature about the Chinese economy since, in December 1978, Deng Xiaoping announced the so-called "reform and opening-up" policy aimed at drastically reforming the national economy from a planned system to a market-oriented economy.
}

is more severe in rural regions and the private sector than those in urban regions and the public sector. Furthermore, we found that, in China, the gender wage gap has been increasing rapidly in recent years.

The remainder of the paper is structured as follows: The next section presents hypotheses to be tested by meta-analysis. Section 3 describes the procedures used in searching and selecting the literature subject to the meta-analysis and overviews the selected studies. Section 4 conducts a meta-synthesis of the collected estimates. Section 5 performs a meta-regression analysis (MRA) of heterogeneity among studies. Section 6 tests 
for publication selection bias. Lastly Sect. 7 summarizes the major findings from the meta-analysis and concludes the paper.

\section{The gender wage gap in China: hypothesis development}

This section reviews the historical background of the market-oriented reforms and economic growth track in China from the latter half of the 1980s, when the Reform and Opening-Up policy (Gaige Kaifang) was enforced, to the present; it then proposes a set of testable hypotheses regarding the gender wage gap for meta-analysis.

During the mid-1980s, Deng Xiaoping's government advanced market-oriented reforms while maintaining a political dictatorship system controlled by the Communist Party of China. The Deng administration enforced the policy of allowing some regions/individuals to become rich faster than other regions/individuals as a fundamental principle of the Reform and OpeningUp policy, and some inequality was tolerated as a result. This represented a breaking away from the philosophy of absolute equality advocated during the era of Mao Zedong. Later, as is well known, China's economic advancement would leap forward, spurred by the adoption of market mechanisms and large-scale opening up to the outside world; at the same time, income inequality grew markedly. In fact, according to Zhang and Zhao (2018), although the Gini coefficient in the early period of the Reform and Opening-up policy was at a low level of 0.20 or less, it began to rise in the $1990 \mathrm{~s}$ and reached nearly 0.40 in 2000 , then 0.50 in 2008, and more than 0.50 in 2009 and beyond. ${ }^{4}$ It is probable that this rapid increase in income inequality may significantly affect the gender wage gap. To understand the real state of the wage gap between male and female workers in China, we propose four hypotheses testable by meta-analysis to answer the following fundamental questions: (1) How large is the gender wage gap in China during the transition period? (2) Do any gender wage gap disparities between urban and rural regions remain? (3) Do any gender wage gap disparities exist between SOEs and POEs? (4) Does the advancement of market-oriented reforms affect the gender wage gap?

\footnotetext{
${ }^{4}$ According to the National Statistics Bureau of China, China's Gini coefficient reached a peak of 0.491 in 2008, then fell to 0.462 by 2015, 0.465 in 2016, and 0.467 in 2017 (https://www.ceicdata.com/zh-hans/china/resident-incom e-distribution/gini-coefficient). However, Zhang and Zhao (2018) pointed out that the recent national census does not cover about $20 \%$ of the national income, which mainly consists of commercial and property income of the high-income class, and, therefore, the Gini coefficient based on the official statistics was seriously underestimated. The problem is also stressed by Li et al. (2017). Zhang and Zhao (2018) argued that, taking account of the existence of non-statistical incomes, the Gini coefficient in China after 2009 is likely to be underestimated by about 0.10 points.
}

It is well known that, during the planned economy period (1949-1977), China emphasized gender equality as an important socialist ideology, and the government enforced it thoroughly by implementing equal employment policies and policies to promote women's labor participation, as demonstrated by the slogan "women hold half of the sky." Therefore, the gender gap in employment, wages, and occupation was much smaller in that era (Meng 2000; Li and Song 2013; Ma 2018a). However, as noted above, since 2000, income inequality in China has expanded; the Gini coefficient was higher than 0.40which is considered to be the warning level for social disorder. There is concern that the worsening income inequality may lead to dissatisfaction with and distrust of the government and social instability (Gu et al. 1995; Liu 1999; Kettl 2018). ${ }^{5}$ Therefore, since the 1980 s, controlling wage levels to restrain income inequality has been an important topic regarding the Chinese economic policy. In that context, some measures have been enacted to limit the wage gap, including state intervention in the wage determination process in the public sector and administrative guidance in the private sector.

How effectively did the Chinese government restrict the wage gap between male and female workers? According to data of international comparison, using the percentage of female wages to male wages, the gender wage gap in China was estimated to be $82.7 \%$ in 2002 (Song et al. 2017), while the same indicator in 2015 stood at $81.1 \%$ in the USA, $82.3 \%$ in the UK, $81.3 \%$ in Germany, $88.0 \%$ in Sweden, $67.6 \%$ in Korea, and $72.2 \%$ in Japan (Japan Institute for Labor Policy and Training 2016). These figures indicate that the gender wage gap is greater in China than in the Nordic social democracy countries but is much smaller than in family-oriented countries such as Korea and Japan and is almost the same as in most developed countries. It seems that the effects of the Chinese government's policies for controlling the gender wage gap in the planned economy period are in evidence here.

We should note, however, that the percentage of female wages to male wages does not capture real gender wage discrimination (i.e., unexplained wage difference between male and female workers), which is estimated after controlling for worker-level characteristics such as educational attainment, years of work experience, skill level, health status, and employment conditions such as occupation, industry sector, company ownership type, and location. Moreover, in China, as a developing country, the

\footnotetext{
${ }_{5}^{5}$ According to an interview survey in 1989, when the Tiananmen Incident took place, the rate of individuals who answered "the expansion of income inequality may cause increasing social instability" reached about 40 percent in China (Gu et al. 1995; Liu 1999).
} 
difference in men's and women's education and employment opportunities are likely to be higher than those in their developed counterparts. Therefore, we expect that, in the results of empirical studies, the gender wage gap in China is evaluated to be lower than that in developed economies.

As we will argue in Sect. 3, in the meta-analysis, for reasons of expediency, the size of an effect in question is used to delineate four categories: (a) economically insignificant effect, (b) small effect, (c) medium effect, and (d) large effect (Doucouliagos 2011). According to Weichselbaumer and Winter-Ebmer (2005), the gender wage gap in developed economies is highly likely at a medium level. Based on the above arguments, regarding the level of the gender wage gap in China during the transition period, we propose the next hypothesis:

H1: The wage effect of gender is small during the transition period.

In rural China, despite the ideological guidance of communism, tradition and custom continue to strongly influence people's thoughts and ways of living. In fact, according to Cheng (2011) and Fen and Xiao (2014), there still remains deep-rooted social awareness, such as male predomination over women and the wisdom of "men for work, women for family" in rural regions even now; as a result, rural women face unreasonable discrimination in various aspects of economic and social activities. Hence, we surmise that, in company activities, discrimination against women is more severe in rural regions than in urban regions where female workers have greater freedom from the constraints of tradition and custom. On this point, rural regions in China do not differ greatly from those of other developing countries.

In China, however, there are special conditions in which the above circumstances are retained for a long period of time, that is the Hukou system and the development of township and village enterprises (TVEs). Since 1958, the Chinese government has implemented the Hukou system, which separates urban and rural regions to control the changes of residence. Under this system, moving from rural regions to urban regions is prohibited, and the migration of labor is strongly restricted. TVEs have developed to absorb the surplus laborers in rural regions under these institutional restrictions (Minami and Ma 2010). During the 1980s, TVEs were operated as collective enterprises managed by people's communes, which is the lower-level state organization in the rural areas. In the 1990s, however, most TVEs were privatized. These privatized TVEs now play a strong role in business activities in rural economies, while the activities of SOEs, in which the impacts of gender equality policies enforced during the planned economy period are remarkably strong, are quite limited. From this perspective, it is worth paying great attention to the arguments of Meng and Miller (1995) and Meng (1998a, b) that closely link discrimination against female workers with the development of TVEs. Therefore, in respect to the difference in the gender wage gap between urban and rural regions, we predict:

$H 2$ : The gender wage gap is greater in rural regions than in urban regions.

Many researchers have pointed out that the contemporary Chinese labor market is segmented by ownership types of companies into the public sector and the private sector (Dong and Bowles 2002; Chen et al. 2005; Démurger et al. 2012; Ma 2018b). Employment conditions for women are also distinguished in the same way. In the era of the planned system, the government strongly promoted gender equality in employment and wages in the entire public sector. In fact, as part of their welfare programs, SOEs strongly supported the continued employment of women with younger children, through means such as successively opening nursery schools and kindergartens. As a consequence, the gender wage gap was controlled and small (Maurer-Fazio and Hughes 2002; Hare 2019). Such favorable employment treatments for women continue in the public sector even now and have served as an important motivation for highly educated women to seek jobs in SOEs in recent years (Liu 2015).

As noted above, while the Chinese government has implemented a wide range of policies to control income inequality, SOEs actually play a major role in such measures. International comparison shows that SOEs in China continue to have a strong influence on wage levels as compared to developed counties in Europe and North America or to the former socialist states of Eastern Europe and the former Soviet Union. During the period of Reform and Opening-Up policies after 1978, POEs grew considerably in China. However, given strong maintenance of the one-party dictatorship system and the gradual reforms, the presence of SOEs in the national economy remains greatly. In fact, according to official statistics, in 2017, the proportions of gross domestic product (GDP) and tax revenue of SOEs to the total national amount are approximately $40 \%$ and $50 \%$, respectively (National Bureau of Statistics of China 2018). Accounting for the fact that SOEs tend to obey the policies of the central government and the party to mitigate income inequality and the influence of the ideology of gender equality on the management of SOEs was maintained strongly even during the transition period, we assume: 
H3: The gender wage gap in SOEs is smaller than in POEs.

Unlike Russia and other Eastern European countries, China still maintains one-party dictatorship in the political sphere and enforces gradualism-based economic reforms. However, the influence of market mechanisms on the activities of companies and citizens is increasing day by day (Hara 2018). As noted above, despite the policy efforts of the Chinese government, the nation's Gini coefficient is increasing steadily. There is no doubt that the remarkable growth of the private sector caused the significant expansion of income inequality. The question is whether the gender wage gap trend is similar to that of income inequality during the transition period.

In theory, the spread of a market mechanism could contribute to reducing the gender wage gap because, in a competitive market, companies should determine wage levels based on a worker's productivity, which may reduce the unreasonable wage discrimination against women. However, the growth of POEs in China may have the opposite effect. Namely, if hypothesis $\mathrm{H}_{3}$ is right, then POEs would have a stronger tendency to discriminate against female workers than would SOEs. As pointed out above, although the public sector still makes great contributions to the creation of added value and tax revenues, the proportion of employees in the private sector to the total workers in urban regions had reached about 80\% (National Bureau of Statistics of China 2018). Furthermore, with the progress of SOE reform, which promotes human resource management autonomy in SOEs, the influence of gender equality policies on the employment and wage decision-making processes in the public sector has been weakened. When discretionary power becomes stronger in the public sector, the organizational behaviors of SOEs would come to resemble those of POEs, and the gender wage gap is likely to increase in the SOEs as well. In China, from the latter half of the 1980s to the present, the rapid growth of POEs and the promotion of management autonomy in SOEs are likely to increase discrimination against female workers in both corporate sectors. Accordingly, we propose testing the following hypothesis regarding the time trend in the gender wage gap during the transition period:

H4: The gender wage gap increases during the transition period.

In the following sections, we examine the above four hypotheses by performing a large-scale meta-analysis of the existing literature.

\section{Literature selection and outlines of selected works for meta-analysis}

This section first describes the procedure for searching and selecting literature suitable for testing the hypotheses proposed in the previous section and then outlines the selected studies for meta-analysis.

A very large number of empirical studies analyzed the wage determinants in China, and a large portion of these previous works employed gender as one independent variable in the wage function. Accordingly, we adopted a policy of searching and selecting literature by collecting as many empirical studies as possible on the wages in China and extracting estimates suited to the meta-analysis in this paper. More concretely, using the electronic academic literature databases of EconLit and Web of Science as well as the websites of leading academic publishers for English language literature ${ }^{6}$ and the Chinese National Knowledge Infrastructure (CNKI) database, which is the largest academic literature database in China for Chinese language literature, we first searched for relevant studies published from 1990 to June 2020. In these databases and websites, we carried out an AND search for article titles using "China" and "wage" as keywords, obtaining 212 English and 163 Chinese papers. ${ }^{7}$ Next, we closely examined the contents of these 375 studies and picked out those that actually examined the gender effect by estimating a wage function. As a result, we finally selected 90 and 109 studies in the English and Chinese languages, respectively. ${ }^{8}$

A breakdown of the 199 selected works by publication year shows that two papers ( $1.0 \%$ of the total) were published during the 1990s, 40 (20.1\%) during the 2000s, 143 (71.8\%) during the 2010s, and 14 (7.0\%) in 2020, faithfully reflecting the growth of empirical analysis in Chinese economic studies in the last decade. This fact implies that the meta-analysis in this paper is largely based on empirical evidence generated from advanced econometric analyses in recent years. This is important for pursuing the true effect of gender on wage levels in China during the transition period.

To test hypotheses $\mathrm{H}_{2}$ and $\mathrm{H}_{3}$ regarding the difference in the gender wage gap between urban and rural regions and between SOEs and POEs, it is essential to have empirical results in which the various types of regions and firms are analyzed separately. The selected

\footnotetext{
${ }^{6}$ They refer to the following six publishers: Emeraldinsight (https://www emeraldinsight.com), Sage Journals (https://journals.sagepub.com), ScienceDirect (https://www.sciencedirect.com), Springer Link (https://link.sprin ger.com), Taylor \& Francis Online (https://www.tandfonline.com), and Wiley Online Library (https://onlinelibrary.wiley.com).

7 The final literature search was conducted in July 2020.

8 A bibliography of the 199 selected works is available in Appendix 1.
} 
studies fully satisfy this requirement. ${ }^{9}$ That is, 119 of the 199 works report estimates of a gender variable for urban regions, while 18 are limited to estimates for rural regions; similarly, 7 works focus solely on SOEs and 10 on POEs. Therefore, although the numbers of previous studies limiting their research subjects to rural regions or to specific ownership type of companies are small, this would not impede the examination of hypotheses $\mathrm{H}_{2}$ and $\mathrm{H}_{3}$ by meta-analysis.

The selected studies are also useful for testing hypotheses $\mathrm{H}_{1}$ and $\mathrm{H}_{4}$, which concern the level of gender wage gap through the transition period and its time-series dynamics. This is true because the periods subject to research in these 199 works as a whole cover the 41-year period from 1978 to 2018, and the estimates can be obtained year by year. ${ }^{10}$ Since only nine of the 199 studies used panel data, the vast majority of estimates reported in the literature are empirical results concerning the gender wage gap in specific years. This fact is advantageous in testing hypothesis $\mathrm{H}_{4}$.

From the 199 selected studies, we extracted a total of 1472 estimates. The mean (median) of the number of collected estimates per study is 7.4 (6). All of these are single-term estimates of gender dummy variables, of which 1165 are male dummy variables, while the remaining 307 are female dummy variables. ${ }^{11}$ In order to focus on discrimination against women in terms of wage level, this paper uses the reversed values of the estimates of male dummy variables together with the estimates of female dummy variables. In other words, the meta-analysis in this paper examines how much lower is the female wage than the male wage in China, ceteris paribus.

Further, in order to correspond to the difference in the units of estimation results in the selected studies, we employ the partial correlation coefficient (PCC) of a corresponding estimate in the meta-analysis. The PCC is a measure of the association of a dependent variable and the independent variable in question when other variables are held constant. When $t_{k}$ and $d f_{k}$ denote the $t$ value and the degree of freedom of the $k$-th estimate,

\footnotetext{
${ }^{9}$ While interaction terms between a gender dummy variable and a regional or corporate-sector dummy variable could be subject to meta-analysis, the selected works included almost no such estimation results.

${ }^{10}$ However, some variation is apparent by period among the empirical results available for use. In fact, the number of estimates on the gender wage gap in the 1980s and the first half of the 1990s averages only 10.7 per year, while the annual averages in the latter half of the 1990s, the 2000s, and the 2010 s rose to $43.8,68.9$, and 52.0, respectively.

${ }^{11}$ Estimates of interaction terms of a gender dummy variable and other independent variables are not included in the meta-analysis in this paper. However, we examine how the simultaneous estimation of an interaction term(s) affects estimates of a single term of a gender dummy in the metaregression estimation in Sect. 5 .
}

respectively, the PCC $\left(r_{k}\right)$ is calculated with the following equation:

$$
r_{k}=\frac{t_{k}}{\sqrt{t_{k}^{2}+d f_{k}}}, k=1,2, \ldots, K
$$

The standard error $\left(S E_{k}\right)$ of $r_{k}$ is given by $\sqrt{\left(1-r_{k}^{2}\right) / d f_{k}}$.

As the evaluation criterion of the correlation coefficient, Cohen (1988) suggested using the values of 0.10 , 0.30 , and 0.50 as cut-offs to distinguish a small effect, medium effect, and large effect, respectively. However, this criterion is set with a zero-order correlation that is the correlation coefficient with no control variables. It is somewhat strict in economics research in which a large number of control variables are usually employed in empirical studies. Therefore, Doucouliagos (2011) proposed $0.048,0.112$, and 0.234 to be the lowest thresholds of small, medium, and large effects, respectively, as the new general standard in labor economics research (ibid., Table 3, p. 11). In this paper, we evaluate the gender wage gap in China in accordance with this standard.

\section{Meta-synthesis}

A meta-analysis ordinarily consists of three steps: (1) meta-synthesis of collected estimates, (2) meta-regression analysis of heterogeneity among the literature, and (3) testing for publication selection bias (Iwasaki 2020a, b). We follow this standard procedure in examining the hypotheses on the gender wage gap in China. Accordingly, in this section, as the first step of meta-analysis, we synthesize 1472 collected estimates using their PCCs after observing their distribution.

Table 1 shows descriptive statistics of the PCCs of the collected estimates and the results of the $t$ test and Shapiro-Wilk normality test, while Fig. 1 displays their kernel density estimations. To match the four hypotheses proposed in Sect. 2, both of these are presented not only for all studies but also for cases in which collected estimates are divided by target regions, corporate sectors, and periods. As described in the preceding section, in the metaanalysis, the reversed values of the estimates of male dummy variables are used together with the estimates of female dummy variables.

According to Table 1, the mean and median of the PCCs for all studies are negative, and Panel (a) of Fig. 1 shows a skewed distribution toward the negative side, with a peak at -0.10 . In other words, the vast majority of empirical results reported in the selected literature indicate that there exists a gender wage gap disadvantageous to women in the Chinese economy. In fact, 1408, or $95.7 \%$, of the 1472 collected estimates have a negative sign. Moreover, according to the Doucouliagos standard, $127(8.6 \%)$ of these 1408 estimates show a large gender 
effect on wage, while 624 (44.3\%) and 493 (35.0\%) indicate medium and small effects, respectively, and the remaining 164 (11.6\%) denote that the gender wage gap is insignificant. In sum, most of the collected estimates suggest that the wage effect of gender has an economically meaningful size in line with hypothesis $\mathrm{H}_{1}$.

As seen in Table 1 and Panels (b) and (c) of Fig. 1, the distributions of collected estimates categorized based on target regions and corporate sectors also support both hypotheses $\mathrm{H}_{2}$ and $\mathrm{H}_{3}$. Actually, estimates related to the gender wage gap in rural regions and POEs are more heavily weighted toward the negative side than those in urban regions and SOEs. Similarly, a difference is apparent in the distributions of estimates by periods as well. In fact, in Panel (d) of Fig. 1, estimates for the 2010s are more strongly deflected to the negative side than those for the 2000s and earlier, which corresponds with hypothesis $\mathrm{H}_{4}$.

Table 2 reports the results of meta-synthesis. In this table, together with synthesis results using the fixedeffect model and the random-effects model, synthesis also was conducted using the unrestricted weighted least squares average (UWA) method, which is less subject to influence from excess heterogeneity than the fixed-effect model and has less publication-selection bias than the random-effects model, and UWA synthesis of estimation results with statistical power of more than 0.80-that is, the weighted average of the adequately powered (WAAP) synthesis (Stanley and Doucouliagos 2017; Stanley et al. 2017). As was the case with Table 1 and Fig. 1, Table 2 also provides results specialized for each hypothesis. Since, in each case, a Cochrane $Q$ test of homogeneity rejects the null hypothesis at a $1 \%$ significance level, and the $I^{2}$ and $H^{2}$ statistics also suggest the presence of heterogeneity in Column (b) of this table, in Column (a), the estimates of the random-effects model are adopted as reference values of the synthesized effect size. On the other hand, under the new UWA synthesis method, in Column (c) of Table 2, WAAP synthesis values, considered more reliable, are used as reference values for comparison with those generated by the random-effects model.

In the results of all studies, the random-effects model produced a synthesis value of -0.122 , while WAAP estimation yielded a value of -0.092 . According to the Doucouliagos standard, if the former shows the true effect size, then it could be said that the wage effect of gender in China would be of a medium size through the transition period, while if the latter is assumed as the true effect size, we could consider that the impact of gender on wage levels would be small. In this way, the traditional and new synthesis methods demonstrate different assessments of the effect size. Hence, we will make a final judgement regarding hypothesis $\mathrm{H}_{1}$ referring to the test results of publication selection bias and the presence of genuine empirical evidence in the selected literature in Sect. 6.

On the other hand, despite the difference in meta-synthesis methods, the results in Table 2 provide support for hypotheses $\mathrm{H}_{2}$ and $\mathrm{H}_{3}$. In fact, both the random-effects and WAAP synthesis values indicate that the effect size of gender on wage levels in urban regions and SOEs is evaluated to be small, while, in rural regions and POEs, the wage effect of gender is considered to have a medium size. The difference between regions and corporate sectors is noteworthy for understanding the wage mechanism in China.

With regard to hypothesis $\mathrm{H}_{4}$, both the random-effects model and the WAAP method produced results that the absolute value of the synthesized effect size tends to become larger from the early period to the current years. To back up these findings, we looked at changes over time in the scale of the gender wage gap through a more detailed subdivision of collected estimates. The results are shown in Fig. 2. The slope of the approximate line in this figure is estimated to be negative and statistically significant at the $1 \%$ level, and its coefficient implies that, as the average estimation period approaches the present time year by year, the gender wage gap increases by 0.0027 in terms of the PCC. As demonstrated in Fig. 2, hypothesis $\mathrm{H}_{4}$ is supported, even when the estimation period is divided into single-year units.

\section{Meta-regression analysis}

While the meta-synthesis of the previous section carried out explicit hypothesis testing by providing a point estimate of the wage effect of gender as a synthesized effect size, it has the drawback of largely excluding from consideration heterogeneity among the literature. Accordingly, this section verifies the reliability of the synthesis results through estimating a meta-regression model that controls simultaneously for various study conditions among the selected studies. More concretely, we estimate a meta-regression model in the form of:

$$
y_{k}=\beta_{0}+\sum_{n=1}^{N} \beta_{n} x_{k n}+e_{k}, k=1, \cdots, K,
$$

where $y_{k}$ is the PCC (i.e., $r_{k}$ ) of the $k$-th estimate, $\beta_{0}$ is the constant, $x_{k n}$ denotes a meta-independent variable that captures the relevant characteristics of an empirical study and explains its systematic variation from other empirical results in the literature, $\beta_{n}$ denotes the metaregression coefficient to be estimated, and $e_{k}$ is the metaregression disturbance term. Following the guidelines of Stanley and Doucouliagos (2012), to check the statistical robustness of coefficient $\beta_{n}$, we performed an MRA using the following seven estimators: (1) the cluster-robust 


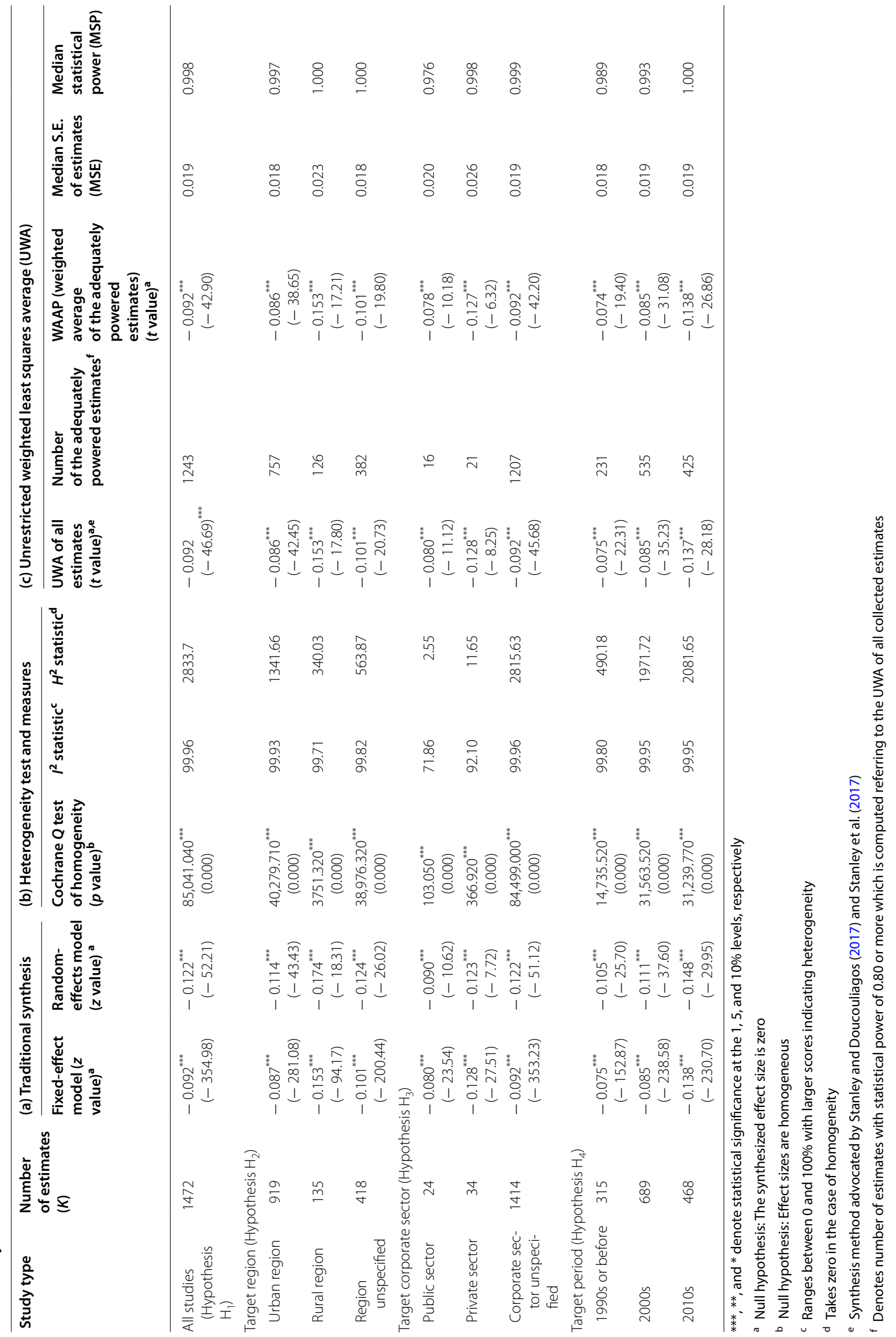




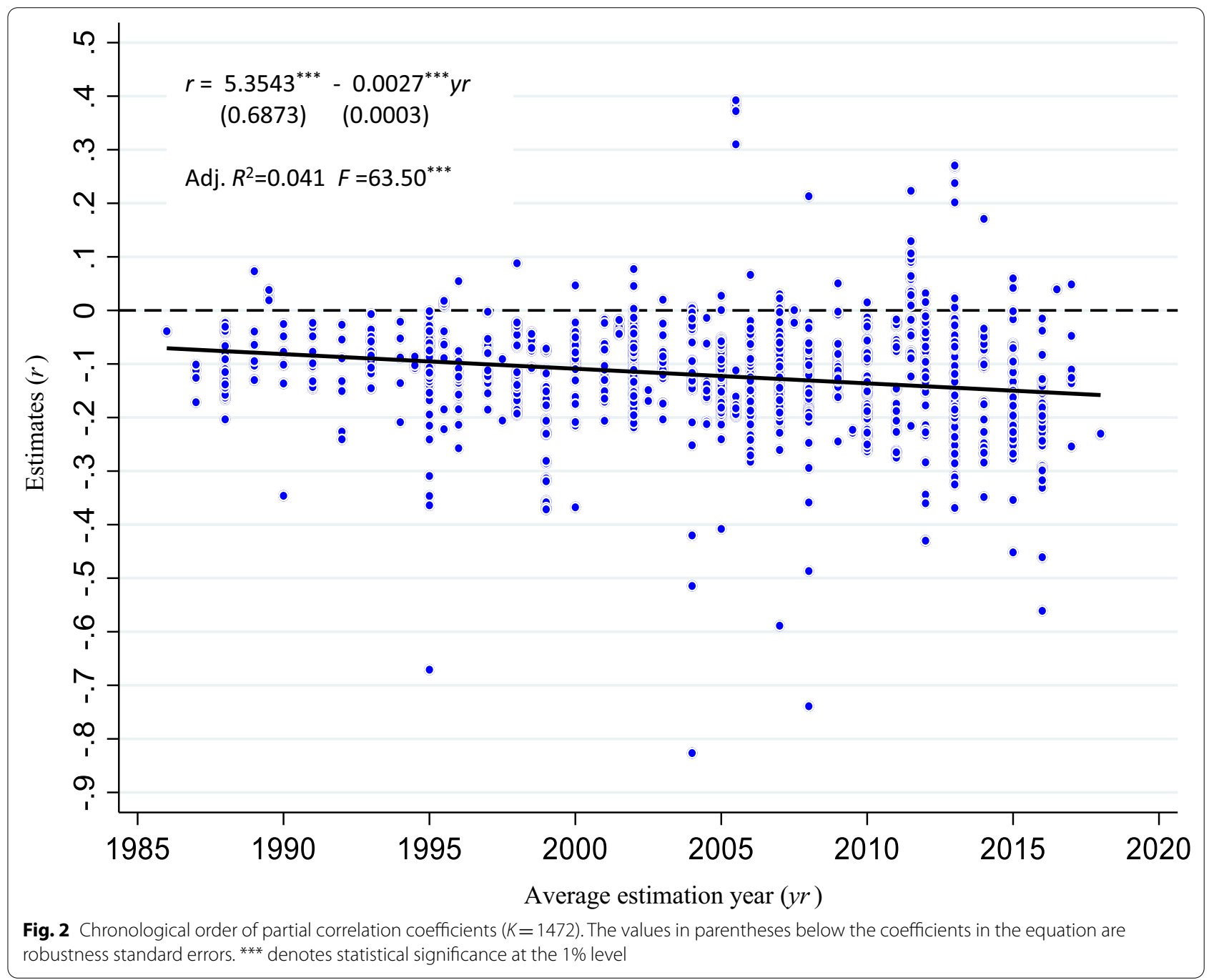

ordinary least squares (OLS) estimator, which clusters the collected estimates by study and computes robust standard errors; the cluster-robust weighted least squares (WLS) estimator using (2) the number of observations $(N)$, (3) the degree of freedom (d.f.), or (4) the inverse of the standard error $(1 / S E)$ as an analytical weight; (5) the multi-level mixed-effects RLM estimator; (6) the clusterrobust random-effects panel GLS estimator, and (7) the cluster-robust fixed-effects panel LSDV (least squares with dummy variable).

On the right-hand side of Eq. (2), in addition to the focused research attributes consisting of target region, corporate sector, and period, a series of variables are introduced to capture the differences in Hukou type, wage level percentile, survey data, data type, wage type, wage payment period, wage variable type, estimator, presence of control for selection bias, selection of control variables, estimation with an interaction term(s), and standard error that also may affect the estimation results in the selected studies. ${ }^{12}$ The names, definitions, and descriptive statistics of these meta-independent variables are listed in Table 3.

Table 4 reports the estimation results. As shown in this table, the signs and statistical significance of some metaindependent variables significantly vary with the choice of estimator. Thus, assuming that meta-independent variables that are statistically significant and have the same sign in at least four of the seven models constitute statistically robust estimation results, we test hypotheses $\mathrm{H}_{2}$ to $\mathrm{H}_{4}$.

\footnotetext{
12 While educational attainment is one of the most important determinants affecting wage levels, since nearly all of the selected studies controlled for this factor in their empirical analyses, the influence of control for this factor was not considered in the MRA in this section.
} 
Table 3 Names, definitions, and descriptive statistics of meta-independent variables

\begin{tabular}{|c|c|c|c|c|}
\hline \multirow[t]{2}{*}{ Variable name } & \multirow[t]{2}{*}{ Definition } & \multicolumn{3}{|c|}{ Descriptive statistics } \\
\hline & & Mean & Median & S.D. \\
\hline Rural region & $1=$ if the target region is a rural region, $0=$ otherwise & 0.092 & 0 & 0.289 \\
\hline Region unspecified & $1=$ if the target region is unspecified, $0=$ otherwise & 0.284 & 0 & 0.451 \\
\hline Public sector & $1=$ if the sample is limited to workers of state-owned enterprises, $0=$ otherwise & 0.016 & 0 & 0.127 \\
\hline Private sector & $1=$ if the sample is limited to workers of privately owned enterprises, $0=$ otherwise & 0.023 & 0 & 0.150 \\
\hline Average estimation year & Average estimation year & 2005.161 & 2006 & 7.008 \\
\hline Urban residents & $1=$ if the sample is limited to workers who are urban residents, $0=$ otherwise & 0.103 & 0 & 0.304 \\
\hline Migrants & $1=$ if the sample is limited to workers who are migrants, $0=$ otherwise & 0.192 & 0 & 0.394 \\
\hline Low-percentile group & $1=$ if the observation is limited to the 30th percentile of the wage level or less, $0=$ otherwise & 0.068 & 0 & 0.252 \\
\hline Middle-percentile group & $1=$ if the observation is limited to the $30-75$ th percentile of the wage level, $0=$ otherwise & 0.063 & 0 & 0.242 \\
\hline High-percentile group & $\begin{array}{l}1=\text { if the observation is limited to the } 75 \text { th percentile of the wage level or more, } 0=\text { other- } \\
\text { wise }\end{array}$ & 0.049 & 0 & 0.216 \\
\hline CHNS & $\begin{array}{l}1=\text { if the survey results of China's Health and Nutrition Survey (CHNS) are used as the data } \\
\text { source, } 0=\text { otherwise }\end{array}$ & 0.119 & 0 & 0.324 \\
\hline CGSS & $\begin{array}{l}1=\text { if the survey results of the Chinese General Social Survey (CGSS) are used as the data } \\
\text { source, } 0=\text { otherwise }\end{array}$ & 0.092 & 0 & 0.290 \\
\hline Other household survey & $\begin{array}{l}1=\text { if the results of a household survey other than CHIP, CHNS, or CGSS are used as the data } \\
\text { source, } 0=\text { otherwise }\end{array}$ & 0.279 & 0 & 0.449 \\
\hline Enterprise survey & $1=$ if the results of an enterprise survey are used as the data source, $0=$ otherwise & 0.063 & 0 & 0.243 \\
\hline Panel survey & $1=$ if the results of a panel survey are used as the data source, $0=$ otherwise & 0.030 & 0 & 0.170 \\
\hline Regular wage & $1=$ if regular wage is employed for empirical analysis, $0=$ otherwise & 0.707 & 1 & 0.455 \\
\hline Monthly & $1=$ if monthly wage is employed for empirical analysis, $0=$ otherwise & 0.340 & 0 & 0.474 \\
\hline Daily & $1=$ if daily wage is employed for empirical analysis, $0=$ otherwise & 0.018 & 0 & 0.134 \\
\hline Hourly & $1=$ if hourly wage is employed for empirical analysis, $0=$ otherwise & 0.408 & 0 & 0.492 \\
\hline Logarithm value & $1=$ if a logarithm value of wage is used as the dependent variable, $0=$ otherwise & 0.865 & 1 & 0.342 \\
\hline OLS & $1=$ if an OLS estimator is used for estimation, $0=$ otherwise & 0.782 & 1 & 0.413 \\
\hline IV/2SLS/3SLS & $1=$ if an IV, $2 S L S$, or $3 S L S$ estimator is used for estimation, $0=$ otherwise & 0.057 & 0 & 0.232 \\
\hline Control for selection bias & $\begin{array}{l}1=\text { if the selection bias due to endogeneous labor participation is controlled for, } 0=\text { other- } \\
\text { wise }\end{array}$ & 0.069 & 0 & 0.254 \\
\hline Occupation & $1=$ if the estimation simultaneously controls for occupation, $0=$ otherwise & 0.307 & 0 & 0.461 \\
\hline Age/age group & $1=$ if the estimation simultaneously controls for age or age group, $0=$ otherwise & 0.247 & 0 & 0.431 \\
\hline Work experience/tenure & $\begin{array}{l}1=\text { if the estimation simultaneously controls for work experience and/or tenure, } 0=\text { other- } \\
\text { wise }\end{array}$ & 0.715 & 1 & 0.451 \\
\hline Health condition & $\begin{array}{l}1=\text { if the estimation simultaneously controls for the health condition of workers, } 0=\text { other- } \\
\text { wise }\end{array}$ & 0.126 & 0 & 0.332 \\
\hline Firm size & $\begin{array}{l}1=\text { if the estimation simultaneously controls for the size of firms to which workers belong, } \\
0=\text { otherwise }\end{array}$ & 0.096 & 0 & 0.295 \\
\hline Trade union & $1=$ if the estimation simultaneously controls for trade unions, $0=$ otherwise & 0.044 & 0 & 0.206 \\
\hline Location fixed effects & $1=$ if the estimation simultaneously controls for location fixed effects, $0=$ otherwise & 0.513 & 1 & 0.500 \\
\hline Industry fixed effects & $1=$ if the estimation simultaneously controls for industry fixed effects, $0=$ otherwise & 0.439 & 0 & 0.496 \\
\hline With an interaction term(s) & $1=$ if the estimation is conducted with an interaction term(s), $0=$ otherwise & 0.011 & 0 & 0.104 \\
\hline S.E. & Standard error of patial correlation coefficient & 0.024 & 0.019 & 0.020 \\
\hline
\end{tabular}

The estimation results in Table 4 indicate that differences in region, corporate sector, and period have a strong impact on the gender wage gap in China, and this finding is robust even after controlling for a series of study conditions from the Hukou type to the standard errors. First, the rural-region variable is estimated with a significant and negative coefficient in six of the seven models, indicating that, when all other conditions are constant, the gender wage gap in rural regions is higher than in urban regions within a range of 0.04020.0618 . Second, while the public-sector variable shows a significant and positive coefficient in five models, 
Table 4 Meta-regression analysis of literature heterogeneity

\begin{tabular}{|c|c|c|c|c|c|c|c|}
\hline $\begin{array}{l}\text { Estimator } \\
\text { (analytical weight } \\
\text { in brackets) }\end{array}$ & $\begin{array}{l}\text { Cluster-robust } \\
\text { OLS }\end{array}$ & $\begin{array}{l}\text { Cluster-robust } \\
\text { WLS }[N]\end{array}$ & $\begin{array}{l}\text { Cluster-robust } \\
\text { WLS [d.f.] }\end{array}$ & $\begin{array}{l}\text { Cluster-robust } \\
\text { WLS }[1 / S E]\end{array}$ & $\begin{array}{l}\text { Multi-level } \\
\text { mixed-effects } \\
\text { RM }\end{array}$ & $\begin{array}{l}\text { Cluster-robust } \\
\text { random-effects } \\
\text { panel GLS }\end{array}$ & $\begin{array}{l}\text { Cluster-robust } \\
\text { fixed-effects } \\
\text { panel LSDV }\end{array}$ \\
\hline $\begin{array}{l}\text { Meta-independent } \\
\text { variable (default } \\
\text { study type)/model }\end{array}$ & [1] & [2] & [3] & [4] & [5] & {$[6]^{\mathrm{a}}$} & {$[7]^{\mathbf{b}}$} \\
\hline \multicolumn{8}{|c|}{ Target region (urban region)—Hypothesis $\mathrm{H}_{2}$} \\
\hline Rural region & $\begin{array}{l}-0.0602^{* * *} \\
(0.020)\end{array}$ & $\begin{array}{r}-0.0355 \\
(0.026)\end{array}$ & $\begin{array}{c}-0.0402^{* *} \\
(0.020)\end{array}$ & $\begin{array}{c}-0.0430^{* *} \\
(0.020)\end{array}$ & $\begin{array}{l}-0.0603^{* * *} \\
(0.022)\end{array}$ & $\begin{array}{l}-0.0602^{* * *} \\
(0.023)\end{array}$ & $\begin{array}{l}-0.0618^{* *} \\
(0.028)\end{array}$ \\
\hline Region unspecified & $\begin{array}{r}0.0013 \\
(0.014)\end{array}$ & $\begin{array}{c}-0.0096 \\
(0.020)\end{array}$ & $\begin{array}{r}0.0027 \\
(0.016)\end{array}$ & $\begin{array}{c}0.0019 \\
(0.016)\end{array}$ & $\begin{array}{r}-0.0025 \\
(0.016)\end{array}$ & $\begin{array}{r}-0.0041 \\
(0.016)\end{array}$ & $\begin{array}{l}-0.0432^{* * *} \\
(0.016)\end{array}$ \\
\hline \multicolumn{8}{|c|}{ Target corporate sector (unspecified)—Hypothesis $\mathrm{H}_{3}$} \\
\hline Public sector & $\begin{array}{l}0.0118 \\
(0.033)\end{array}$ & $\begin{array}{l}0.0218^{* *} \\
(0.010)\end{array}$ & $\begin{array}{l}0.0096 \\
(0.026)\end{array}$ & $\begin{array}{l}0.0093^{*} \\
(0.005)\end{array}$ & $\begin{array}{l}0.0235^{* *} \\
(0.008)\end{array}$ & $\begin{array}{l}0.024^{* *} \\
(0.011)\end{array}$ & $\begin{array}{l}0.0242^{* *} \\
(0.011)\end{array}$ \\
\hline Private sector & $\begin{array}{c}-0.0244 \\
(0.028)\end{array}$ & $\begin{array}{r}-0.0090 \\
(0.024)\end{array}$ & $\begin{array}{r}-0.0251 \\
(0.026)\end{array}$ & $\begin{array}{r}-0.0265 \\
(0.027)\end{array}$ & $\begin{array}{l}0.0012 \\
(0.019)\end{array}$ & $\begin{array}{l}0.0015 \\
(0.019)\end{array}$ & $\begin{array}{r}-0.0015 \\
(0.017)\end{array}$ \\
\hline \multicolumn{8}{|c|}{ Estimation period_-Hypothesis $\mathrm{H}_{4}$} \\
\hline $\begin{array}{l}\text { Average estimation } \\
\text { year }\end{array}$ & $\begin{array}{l}-0.0031^{* * *} \\
(0.001)\end{array}$ & $\begin{array}{c}-0.0018^{*} \\
(0.001)\end{array}$ & $\begin{array}{l}-0.0030^{* * *} \\
(0.001)\end{array}$ & $\begin{array}{l}-0.0031^{* * *} \\
(0.001)\end{array}$ & $\begin{array}{c}-0.0013^{*} \\
(0.001)\end{array}$ & $\begin{array}{c}-0.0012^{*} \\
(0.001)\end{array}$ & $\begin{array}{c}-0.0010 \\
(0.001)\end{array}$ \\
\hline \multicolumn{8}{|c|}{ Hukou types (Hukou unspecified) } \\
\hline Urban residents & $\begin{array}{r}0.0061 \\
(0.019)\end{array}$ & $\begin{array}{c}-0.0168 \\
(0.014)\end{array}$ & $\begin{array}{r}-0.0067 \\
(0.015)\end{array}$ & $\begin{array}{c}-0.0063 \\
(0.016)\end{array}$ & $\begin{array}{c}0.0119 \\
(0.011)\end{array}$ & $\begin{array}{l}0.0120 \\
(0.011)\end{array}$ & $\begin{array}{l}0.0114 \\
(0.014)\end{array}$ \\
\hline Migrants & $\begin{array}{c}-0.0222^{*} \\
(0.013)\end{array}$ & $\begin{array}{c}-0.0059 \\
(0.028)\end{array}$ & $\begin{array}{c}-0.0156 \\
(0.016)\end{array}$ & $\begin{array}{c}-0.0160 \\
(0.016)\end{array}$ & $\begin{array}{c}-0.0138 \\
(0.013)\end{array}$ & $\begin{array}{c}-0.0140 \\
(0.014)\end{array}$ & $\begin{array}{c}-0.0153 \\
(0.019)\end{array}$ \\
\hline \multicolumn{8}{|c|}{ Wage level percentile (wage level unspecified) } \\
\hline $\begin{array}{l}\text { Low-percentile } \\
\text { group }\end{array}$ & $\begin{array}{l}0.0543^{* * *} \\
(0.018)\end{array}$ & $\begin{array}{r}-0.0071 \\
(0.024)\end{array}$ & $\begin{array}{l}0.0273 \\
(0.022)\end{array}$ & $\begin{array}{l}0.0276 \\
(0.023)\end{array}$ & $\begin{array}{c}0.0299 \\
(0.017)\end{array}$ & $\begin{array}{l}0.0278 \\
(0.017)\end{array}$ & $\begin{array}{l}0.0180 \\
(0.020)\end{array}$ \\
\hline $\begin{array}{l}\text { Middle-percentile } \\
\text { group }\end{array}$ & $\begin{array}{l}0.0473^{* * *} \\
(0.018)\end{array}$ & $\begin{array}{l}0.0133 \\
(0.020)\end{array}$ & $\begin{array}{l}0.0355^{*} \\
(0.020)\end{array}$ & $\begin{array}{l}0.0367 \\
(0.020)\end{array}$ & $\begin{array}{l}0.0168 \\
(0.018)\end{array}$ & $\begin{array}{l}0.0145 \\
(0.018)\end{array}$ & $\begin{array}{l}0.0040 \\
(0.022)\end{array}$ \\
\hline $\begin{array}{l}\text { High-percentile } \\
\text { group }\end{array}$ & $\begin{array}{l}0.0666^{* * *} \\
(0.015)\end{array}$ & $\begin{array}{l}0.0256^{* * *} \\
(0.019)\end{array}$ & $\begin{array}{l}0.0543^{* * *} \\
(0.015)\end{array}$ & $\begin{array}{l}0.0556^{* * *} \\
(0.016)\end{array}$ & $\begin{array}{l}0.0373^{* *} \\
(0.016)\end{array}$ & $\begin{array}{l}0.0351^{* *} \\
(0.017)\end{array}$ & $\begin{array}{r}0.0251 \\
(0.021)\end{array}$ \\
\hline \multicolumn{8}{|l|}{ Survey data (CHIPs) } \\
\hline CHNS & $\begin{array}{c}-0.0109 \\
(0.017)\end{array}$ & $\begin{array}{c}0.0345 \\
(0.021)\end{array}$ & $\begin{array}{c}0.0013 \\
(0.017)\end{array}$ & $\begin{array}{c}0.0020 \\
(0.017)\end{array}$ & $\begin{array}{c}-0.0030 \\
(0.017)\end{array}$ & $\begin{array}{c}-0.0016 \\
(0.017)\end{array}$ & $\begin{array}{c}-0.0204 \\
(0.006)\end{array}$ \\
\hline CGSS & $\begin{array}{c}-0.0093 \\
(0.018)\end{array}$ & $\begin{array}{c}0.0274 \\
(0.027)\end{array}$ & $\begin{array}{l}0.0026 \\
(0.021)\end{array}$ & $\begin{array}{c}0.0029 \\
(0.021)\end{array}$ & $\begin{array}{l}0.0036 \\
(0.019)\end{array}$ & $\begin{array}{c}0.0052 \\
(0.020)\end{array}$ & $\begin{array}{l}0.0356 \\
(0.012)\end{array}$ \\
\hline $\begin{array}{l}\text { Other household } \\
\text { survey }\end{array}$ & $\begin{array}{r}0.0151 \\
(0.013)\end{array}$ & $\begin{array}{l}0.0253 \\
(0.015)\end{array}$ & $\begin{array}{r}0.0171 \\
(0.013)\end{array}$ & $\begin{array}{l}0.0169 \\
(0.013)\end{array}$ & $\begin{array}{l}0.0160 \\
(0.014)\end{array}$ & $\begin{array}{c}0.0159 \\
(0.014)\end{array}$ & \\
\hline Enterprise survey & $\begin{array}{c}-0.0076 \\
(0.027)\end{array}$ & $\begin{array}{c}-0.0092 \\
(0.046)\end{array}$ & $\begin{array}{c}-0.0126 \\
(0.034)\end{array}$ & $\begin{array}{c}-0.0124 \\
(0.034)\end{array}$ & $\begin{array}{l}0.0205 \\
(0.034)\end{array}$ & $\begin{array}{l}0.0206 \\
(0.035)\end{array}$ & \\
\hline \multicolumn{8}{|c|}{ Data type (Cross-section data) } \\
\hline Panel data & $\begin{array}{c}0.0249 \\
(0.023)\end{array}$ & $\begin{array}{c}-0.0018 \\
(0.038)\end{array}$ & $\begin{array}{c}0.0117 \\
(0.028)\end{array}$ & $\begin{array}{l}0.0123 \\
(0.029)\end{array}$ & $\begin{array}{l}0.0196 \\
(0.019)\end{array}$ & $\begin{array}{c}0.0207 \\
(0.019)\end{array}$ & $\begin{array}{l}0.0197 \\
(0.020)\end{array}$ \\
\hline \multicolumn{8}{|c|}{ Wage type (Bonus wage) } \\
\hline Regular wage & $\begin{array}{c}-0.0099 \\
(0.014)\end{array}$ & $\begin{array}{r}-0.0007 \\
(0.016)\end{array}$ & $\begin{array}{c}-0.0056 \\
(0.014)\end{array}$ & $\begin{array}{c}-0.0059 \\
(0.014)\end{array}$ & $\begin{array}{r}-0.0091 \\
(0.009)\end{array}$ & $\begin{array}{c}-0.0083 \\
(0.009)\end{array}$ & $\begin{array}{c}0.0013 \\
(0.003)\end{array}$ \\
\hline \multicolumn{8}{|c|}{ Wage payment period (annual) } \\
\hline Monthly & $\begin{array}{l}0.0292^{*} \\
(0.017)\end{array}$ & $\begin{array}{r}-0.0047 \\
(0.014)\end{array}$ & $\begin{array}{l}0.0129 \\
(0.016)\end{array}$ & $\begin{array}{l}0.0128 \\
(0.016)\end{array}$ & $\begin{array}{c}0.0079 \\
(0.013)\end{array}$ & $\begin{array}{l}0.0056 \\
(0.013)\end{array}$ & $\begin{array}{c}-0.0123^{*} \\
(0.007)\end{array}$ \\
\hline Daily & $\begin{array}{r}0.0271 \\
(0.029)\end{array}$ & $\begin{array}{c}-0.0449^{* *} \\
(0.022)\end{array}$ & $\begin{array}{c}-0.0142 \\
(0.023)\end{array}$ & $\begin{array}{r}-0.0130 \\
(0.024)\end{array}$ & $\begin{array}{l}0.0391^{*} \\
(0.021)\end{array}$ & $\begin{array}{l}0.0378^{*} \\
(0.020)\end{array}$ & \\
\hline Hourly & $\begin{array}{l}0.0414^{* *} \\
(0.017)\end{array}$ & $\begin{array}{r}-0.0007 \\
(0.019)\end{array}$ & $\begin{array}{c}0.0219 \\
(0.017)\end{array}$ & $\begin{array}{c}0.0224 \\
(0.017)\end{array}$ & $\begin{array}{l}0.0223^{* *} \\
(0.011)\end{array}$ & $\begin{array}{l}0.0217^{* *} \\
(0.010)\end{array}$ & $\begin{array}{l}0.0178^{* * *} \\
(0.004)\end{array}$ \\
\hline \multicolumn{8}{|c|}{ Wage variable type (actual value: Yuan) } \\
\hline Logarithm value & $\begin{array}{l}0.0281^{*} \\
(0.016)\end{array}$ & $\begin{array}{c}0.0243 \\
(0.015)\end{array}$ & $\begin{array}{c}0.0274 \\
(0.014)\end{array}$ & $\begin{array}{l}0.0270^{*} \\
(0.014)\end{array}$ & $\begin{array}{c}0.0123 \\
(0.012)\end{array}$ & $\begin{array}{l}0.0096 \\
(0.011)\end{array}$ & $\begin{array}{r}-0.0130 \\
(0.008)\end{array}$ \\
\hline
\end{tabular}


Table 4 (continued)

\begin{tabular}{|c|c|c|c|c|c|c|c|}
\hline $\begin{array}{l}\text { Estimator } \\
\text { (analytical weight } \\
\text { in brackets) }\end{array}$ & $\begin{array}{l}\text { Cluster-robust } \\
\text { OLS }\end{array}$ & $\begin{array}{l}\text { Cluster-robust } \\
\text { WLS }[N]\end{array}$ & $\begin{array}{l}\text { Cluster-robust } \\
\text { WLS [d.f.] }\end{array}$ & $\begin{array}{l}\text { Cluster-robust } \\
\text { WLS }[1 / S E]\end{array}$ & $\begin{array}{l}\text { Multi-level } \\
\text { mixed-effects } \\
\text { RM }\end{array}$ & $\begin{array}{l}\text { Cluster-robust } \\
\text { random-effects } \\
\text { panel GLS }\end{array}$ & $\begin{array}{l}\text { Cluster-robust } \\
\text { fixed-effects } \\
\text { panel LSDV }\end{array}$ \\
\hline $\begin{array}{l}\text { Meta-independent } \\
\text { variable (default } \\
\text { study type)/model }\end{array}$ & {$[1]$} & {$[2]$} & [3] & [4] & [5] & {$[6]^{\mathrm{a}}$} & {$[7]^{b}$} \\
\hline \multicolumn{8}{|l|}{ Estimator } \\
\hline $\begin{array}{l}\text { OLS (estimators } \\
\text { other than OLS) }\end{array}$ & $\begin{array}{l}0.0135 \\
(0.016)\end{array}$ & $\begin{array}{l}0.0103 \\
(0.017)\end{array}$ & $\begin{array}{l}0.0162 \\
(0.016)\end{array}$ & $\begin{array}{l}0.0163 \\
(0.016)\end{array}$ & $\begin{array}{l}0.0064 \\
(0.014)\end{array}$ & $\begin{array}{l}0.0058 \\
(0.014)\end{array}$ & $\begin{array}{l}0.0026 \\
(0.015)\end{array}$ \\
\hline IV/2SLS/3SLS & $\begin{array}{c}0.0059 \\
(0.016)\end{array}$ & $\begin{array}{c}-0.0112 \\
(0.010)\end{array}$ & $\begin{array}{l}0.0002 \\
(0.015)\end{array}$ & $\begin{array}{l}0.0005 \\
(0.015)\end{array}$ & $\begin{array}{l}0.0122 \\
(0.010)\end{array}$ & $\begin{array}{l}0.0119 \\
(0.010)\end{array}$ & $\begin{array}{l}0.0105 \\
(0.011)\end{array}$ \\
\hline $\begin{array}{l}\text { Control for selec- } \\
\text { tion bias }\end{array}$ & $\begin{array}{l}0.0609^{* *} \\
(0.027)\end{array}$ & $\begin{array}{l}0.0639^{* *} \\
(0.030)\end{array}$ & $\begin{array}{l}0.0679 * * \\
(0.029)\end{array}$ & $\begin{array}{l}0.0696^{* *} \\
(0.029)\end{array}$ & $\begin{array}{l}0.0615^{* * *} \\
(0.021)\end{array}$ & $\begin{array}{l}0.0607^{* * *} \\
(0.022)\end{array}$ & $\begin{array}{l}0.0556^{* *} \\
(0.024)\end{array}$ \\
\hline \multicolumn{8}{|l|}{ Control variables } \\
\hline Occupation & $\begin{array}{l}0.0007 \\
(0.011)\end{array}$ & $\begin{array}{r}-0.0010 \\
(0.013)\end{array}$ & $\begin{array}{r}-0.0024 \\
(0.011)\end{array}$ & $\begin{array}{r}-0.0026 \\
(0.011)\end{array}$ & $\begin{array}{c}0.0102 \\
(0.008)\end{array}$ & $\begin{array}{l}0.0097 \\
(0.007)\end{array}$ & $\begin{array}{l}0.0056 \\
(0.007)\end{array}$ \\
\hline Age & $\begin{array}{c}-0.0123 \\
(0.015)\end{array}$ & $\begin{array}{l}0.0234^{* *} \\
(0.011)\end{array}$ & $\begin{array}{l}0.0055 \\
(0.015)\end{array}$ & $\begin{array}{c}0.0065 \\
(0.015)\end{array}$ & $\begin{array}{l}0.0115 \\
(0.017)\end{array}$ & $\begin{array}{l}0.0146 \\
(0.018)\end{array}$ & $\begin{array}{r}0.0871 \\
(0.071)\end{array}$ \\
\hline $\begin{array}{l}\text { Work experience/ } \\
\text { tenure }\end{array}$ & $\begin{array}{c}-0.0024 \\
(0.015)\end{array}$ & $\begin{array}{r}0.0161 \\
(0.015)\end{array}$ & $\begin{array}{r}-0.0005 \\
(0.015)\end{array}$ & $\begin{array}{r}0.0007 \\
(0.015)\end{array}$ & $\begin{array}{c}0.0080 \\
(0.014)\end{array}$ & $\begin{array}{c}0.0082 \\
(0.014)\end{array}$ & $\begin{array}{r}-0.0091 \\
(0.009)\end{array}$ \\
\hline Health status & $\begin{array}{c}-0.0004 \\
(0.016)\end{array}$ & $\begin{array}{r}-0.0141 \\
(0.029)\end{array}$ & $\begin{array}{r}-0.0117 \\
(0.020)\end{array}$ & $\begin{array}{r}-0.0111 \\
(0.020)\end{array}$ & $\begin{array}{c}-0.0062 \\
(0.012)\end{array}$ & $\begin{array}{r}-0.0050 \\
(0.012)\end{array}$ & $\begin{array}{c}0.0093 \\
(0.018)\end{array}$ \\
\hline Firm size & $\begin{array}{c}-0.0310^{*} \\
(0.017)\end{array}$ & $\begin{array}{c}0.0031 \\
(0.026)\end{array}$ & $\begin{array}{c}-0.0129 \\
(0.020)\end{array}$ & $\begin{array}{c}-0.0131 \\
(0.020)\end{array}$ & $\begin{array}{r}-0.0317 \\
(0.015)\end{array}$ & $\begin{array}{r}-0.0331 \\
(0.015)\end{array}$ & $\begin{array}{c}-0.0416 \\
(0.017)\end{array}$ \\
\hline Trade union & $\begin{array}{c}-0.0134 \\
(0.030)\end{array}$ & $\begin{array}{l}0.1234^{* *} \\
(0.054)\end{array}$ & $\begin{array}{l}0.0634 \\
(0.051)\end{array}$ & $\begin{array}{l}0.0643 \\
(0.051)\end{array}$ & $\begin{array}{l}0.0023 \\
(0.021)\end{array}$ & $\begin{array}{l}0.0045 \\
(0.021)\end{array}$ & $\begin{array}{r}0.0331 \\
(0.001)\end{array}$ \\
\hline $\begin{array}{l}\text { Location fixed } \\
\text { effects }\end{array}$ & $\begin{array}{c}-0.0173^{*} \\
(0.010)\end{array}$ & $\begin{array}{l}-0.0383^{* * *} \\
(0.011)\end{array}$ & $\begin{array}{c}-0.0228^{* *} \\
(0.011)\end{array}$ & $\begin{array}{c}-0.0224^{* *} \\
(0.011)\end{array}$ & $\begin{array}{r}-0.0020 \\
(0.011)\end{array}$ & $\begin{array}{r}-0.0015 \\
(0.011)\end{array}$ & $\begin{array}{l}0.0007 \\
(0.014)\end{array}$ \\
\hline $\begin{array}{l}\text { Industry fixed } \\
\text { effects }\end{array}$ & $\begin{array}{c}-0.0003 \\
(0.011)\end{array}$ & $\begin{array}{c}-0.0048 \\
(0.012)\end{array}$ & $\begin{array}{c}0.0004 \\
(0.010)\end{array}$ & $\begin{array}{r}-0.0006 \\
(0.010)\end{array}$ & $\begin{array}{l}0.0068 \\
(0.007)\end{array}$ & $\begin{array}{c}0.0084 \\
(0.007)\end{array}$ & $\begin{array}{l}0.0186^{* *} \\
(0.008)\end{array}$ \\
\hline \multicolumn{8}{|c|}{ Estimation with an interaction term(s) } \\
\hline $\begin{array}{l}\text { With an interaction } \\
\text { term(s) (without } \\
\text { interaction term) }\end{array}$ & $\begin{array}{l}0.0115 \\
(0.024)\end{array}$ & $\begin{array}{c}-0.0099 \\
(0.031)\end{array}$ & $\begin{array}{c}-0.0060 \\
(0.030)\end{array}$ & $\begin{array}{c}-0.0046 \\
(0.030)\end{array}$ & $\begin{array}{l}0.0580^{* *} \\
(0.023)\end{array}$ & $\begin{array}{l}0.0595^{* * *} \\
(0.023)\end{array}$ & $\begin{array}{l}0.0685^{* * * *} \\
(0.020)\end{array}$ \\
\hline \multicolumn{8}{|c|}{ Standard error of patial correlation coefficient } \\
\hline S.E. & $\begin{array}{r}-0.1144 \\
(0.451)\end{array}$ & $\begin{array}{c}-1.3543^{* *} \\
(0.591)\end{array}$ & $\begin{array}{c}-0.3644 \\
(0.467)\end{array}$ & $\begin{array}{r}-0.3941 \\
(0.473)\end{array}$ & $\begin{array}{c}0.0744 \\
(0.427)\end{array}$ & $\begin{array}{l}0.0957 \\
(0.431)\end{array}$ & $\begin{array}{l}0.2105 \\
(0.433)\end{array}$ \\
\hline Constant & $\begin{array}{l}6.0190^{* * *} \\
(1.619)\end{array}$ & $\begin{array}{c}3.5734^{*} \\
(2.100)\end{array}$ & $\begin{array}{l}5.9380^{* * *} \\
(1.703)\end{array}$ & $\begin{array}{l}5.9800^{* * *} \\
(1.719)\end{array}$ & $\begin{array}{l}2.4447^{*} \\
(1.488)\end{array}$ & $\begin{array}{l}2.3147 \\
(1.550)\end{array}$ & $\begin{array}{c}1.8033 \\
(1.819)\end{array}$ \\
\hline K & 1472 & 1472 & 1472 & 1472 & 1472 & 1472 & 1472 \\
\hline$R^{2}$ & 0.200 & 0.338 & 0.194 & 0.192 & - & 0.119 & 0.011 \\
\hline
\end{tabular}

a Breusch-Pagan test: $X^{2}=1069.27, p=0.0000$

b Hausman test: $X^{2}=29.50, p=0.4913$

Figures in parentheses beneath the regression coefficients are robust standard errors. ${ }^{* * *}$, **, and *denote statistical significance at the 1,5 , and $10 \%$ levels, respectively

Source: See Table 3 for the definitions and descriptive statistics of meta-independent variables

the private-sector variable is insignificant in any of the seven models. These results can be interpreted that the gender wage gap is significantly smaller in SOEs than in POEs. Third, the average estimation year is estimated to be significant and negative in six models, and its coefficients imply that, as the estimation period approaches the current time year by year, the gender wage gap increases within a range of $0.0012-0.0031$. This result is highly consistent with the estimation results of the approximate line in Fig. 2. In sum, the results of metaregression analysis provide overall support for the synthesis results reported in the preceding section.

The estimation results in Table 4 also make it clear that, in addition to differences in the target region, corporate sector, and period, wage percentile, wage payment period, control for sample selection bias, firm size, and location 
fixed effects generated systematic disparity in the empirical results of previous studies. These findings also serve as important hints for deeper understanding of the research outcomes on the gender wage gap in China. ${ }^{13}$

\section{Testing for publication selection bias}

As seen above, the results of both meta-synthesis and MRA support the hypotheses presented in Sect. 2. However, the reliability of these test results cannot be established if the selected studies did not contain genuine evidence due to publication selection bias. Publication selection bias occurs when either researchers, reviewers, or editors are inclined to publish research results that are consistent with the conventional view and/or are statistically significant; as a consequence, an effect in question tends to be overvalued in the research record (Iwasaki 2020a, b). Stanley and Doucouliagos (2012) pointed out that "the real problem of publication selection is not its existence, but the large biases that it can impact upon any summary of empirical economic knowledge, when uncorrected" (p. 52). Therefore, we should tackle this issue as one of the important missions of meta-analysis. Accordingly, as the final stage of the meta-analysis, this section tests for publication selection bias and the presence of the true effect. To this end, in addition to visual examination using a funnel plot, we conduct a funnel-asymmetry test (FAT), a precision-effect test (PET), and a precisioneffect estimate with standard error (PEESE), which were proposed by Stanley and Doucouliagos (2012) and have been used widely in previous meta-studies. ${ }^{14}$

Figure 3 exhibits a funnel plot of all studies. In this figure, the collected estimates show a skewed distribution toward the left side, leading to suspicions there is a publication selection bias in the literature. Actually, if the true value is assumed to be zero, the ratio of positive to negative estimates is 64:1408; therefore, the null hypothesis that the number of positive estimates equals the number of negative estimates is strongly rejected $(z=$ $-35.0304, p=0.000$ ). Even if the synthesis value of the random-effects model is assumed to be the true effect, the collected estimates are divided into a ratio of 779:693 with a value of -0.122 being the threshold, and the test of proportions rejects the null hypothesis $(z=2.2415$, $p=0.0250$ ). Furthermore, if we assume that the WAAP synthesis value presents the true effect size, then the collected estimates are distributed at a ratio of 902:570 on

\footnotetext{
${ }^{13}$ To tackle with the issue of model uncertainly, we performed supplement regressions using the Bayesian model averaging (BMA) and the frequentist check OLS model and confirmed that the key variables in Table 4 shows robust estimates in these BMA and OLS models.

14 Appendix 2 describes the methodology of publication selection bias testing performed in this section.
}

the left and right sides with a threshold of -0.092 . As a result, the null hypothesis of proportional distribution is again rejected at the $1 \%$ significance level $(z=-8.653$, $p=0.000$ ). To sum up, both visual verification using the funnel plot and the univariate test results strongly suggest that publication selection bias is very likely to have occurred in this research field regardless of the differences in the assumptions of the true value of a gender effect on wage levels.

The results of the FAT-PET-PEESE test procedure are shown in Table 5. In Panel (a) of the table, the FAT rejects the null hypothesis that the intercept $\left(\gamma_{0}\right)$ is zero for all five models. This result implies that the collected estimates lack funnel asymmetry due to strong publication selection bias. However, even in the presence of publication selection bias, there is a possibility that genuine evidence is available in the selected literature. As shown in Panel (a) of Table 5, the PET rejects the null hypothesis that the coefficient $\left(\gamma_{1}\right)$ of the inverse of the standard errors $(1 / S E)$ is zero in all models, suggesting that the collected estimates do contain empirical evidence regarding the true effect size. Accordingly, looking at the results of the PEESE approach as reported in Panel (b) of the table, we confirm that, in all five models, the coefficients $\left(\gamma_{1}\right)$ of $1 / S E$ are estimated to be statistically significant and, therefore, the true value of the gender wage effect in China should be in a range of -0.0885 to -0.0797 . The value of this publication-selection-bias-adjusted effect size is closer to the WAAP synthesis value $(-0.092)$ than the random-effects one $(-0.122)$. This result agrees with the argument by Stanley et al. (2017) that, as compared with the traditional synthesis method, the WAAP method is much more robust from publication selection bias. From these results, we judge that, while the gender wage gap does exist in China, in accordance with the Doucouliagos standard, the gender effect has remained at a small level throughout the transition period. In other words, as the synthesis result based on the WAAP method does, the test results of publication selection bias and the presence of genuine empirical evidence strongly support hypothesis $\mathrm{H}_{1}$.

We also carried out the FAT-PET-PEESE procedure separately by target regions, corporate sectors, and periods. The results, as well as those for all studies, are summarized in Table 6. As this table shows, the FAT detects publication selection bias in five of nine cases. However, the PET indicates the presence of genuine empirical evidence in all of these nine cases; furthermore, the PEESE method generates a statistically significant non-zero publication-selection-bias-corrected effect size in all cases. The estimated true effects for regions and corporate sectors definitely back up hypotheses $\mathrm{H}_{2}$ and $\mathrm{H}_{3}$. We also confirm that the size of the gender wage gap is greater for 


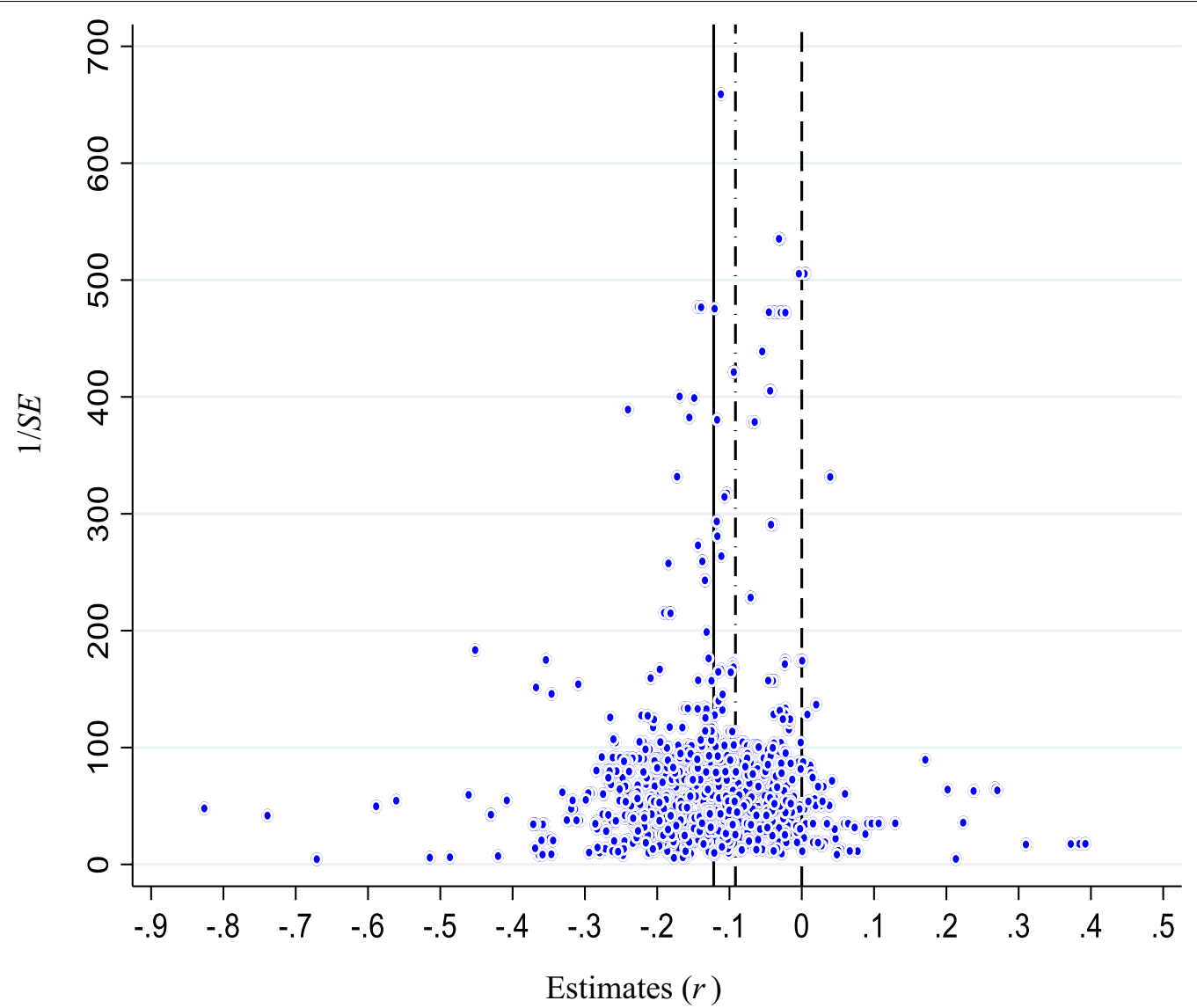

Fig. 3 Funnel plot of patial correlation coefficients $(K=1472)$. The solid line indicates the synthesized effect size by random effects of all studies, while the one-dot chain line indicates the synthesized effect size by WAAP estimation as reported in Table 2

the period of the 2010s than for the period of the 2000s and earlier, which is in line with hypothesis $\mathrm{H}_{4}$. Accordingly, we can say that the meta-analysis in this paper provides results consistent with all of the hypotheses regarding the gender wage gap in China.

\section{Conclusions}

In China, income inequality is becoming a severe economic and social problem, and the gender wage gap is an important factor in this respect. Hence, over the last decades, numerous researchers have attempted econometric analyses concerning the wage effect of gender; as a result, we now have a large mass of empirical evidence on this issue. However, the real scale of the gender wage gap is unclear, as are disparities among regions, corporate sectors, and periods. To approach these unresolved issues, we conducted a meta-analysis that utilized 1472 estimates extracted from 199 previous studies. The notable findings obtained from the meta-analysis in this paper can be summarized in the following three points:
First, the empirical results in the extant literature, which covers a period from 1978 to 2018, show that, although the gender wage gap in China is statistically significant and economically meaningful, it remains at a low level, according to the Doucouliagos standard. In this sense, the effect size of gender on wage levels in China through the transition period has been relatively low compared to that in developed countries where the gender wage gap has medium or even higher scales (Weichselbaumer and Winter-Ebmer 2005). We interpret this result to mean that, unlike in transition economies in Eastern Europe and the former Soviet Union, the socialist philosophy and institutions that treat male and female workers equally continue to be maintained in Chinese society even under systemic transformation to a market economy.

Second, the wage effect of gender differs greatly between regions and corporate sectors in the sense that wage discrimination against women is greater in rural regions and POEs than in urban regions and SOEs. In fact, while the gender wage gap in urban regions and SOEs is evaluated 
Table 5 Meta-regression analysis of publication selection bias

\begin{tabular}{|c|c|c|c|c|c|}
\hline \multicolumn{6}{|c|}{ (a) FAT-PET test (Equation: $\left.t=\gamma_{0}+\gamma_{1}(1 / S E)+v\right)$} \\
\hline Estimator & OLS & Cluster-robust OLS & $\begin{array}{l}\text { Multi-level mixed- } \\
\text { effects RML }\end{array}$ & $\begin{array}{l}\text { Cluster-robust random- } \\
\text { effects panel GLS }\end{array}$ & $\begin{array}{l}\text { Cluster-robust } \\
\text { fixed-effects panel } \\
\text { LSDV }\end{array}$ \\
\hline Model & {$[1]$} & {$[2]$} & [3] & {$[4]^{a}$} & {$[5]^{\mathbf{b}}$} \\
\hline Intercept (FAT: $\left.\mathrm{H}_{0}: \gamma_{0}=0\right)$ & $-2.8691^{* * *}(0.480)$ & $-2.8691^{* * *}(0.870)$ & $-2.7968^{* * *}(0.820)$ & $-2.7870^{* * *}(0.832)$ & $-2.7526^{* * *}(1.013)$ \\
\hline 1/SE (PET: $\left.\mathrm{H}_{0}: \gamma_{1}=0\right)$ & $-0.0721^{* * *}(0.008)$ & $-0.0721^{* * *}(0.015)$ & $-0.0721^{* * *}(0.013)$ & $-0.0722^{* * *}(0.013)$ & $-0.0737^{* * *}(0.014)$ \\
\hline K & 1472 & 1472 & 1472 & 1472 & 1472 \\
\hline$R^{2}$ & 0.335 & 0.335 & - & 0.335 & 0.335 \\
\hline \multicolumn{6}{|c|}{ (b) PEESE approach (Equation: $t=\gamma_{0} \mathrm{SE}+\gamma_{1}(1 / \mathrm{SE})+v$ ) } \\
\hline Estimator & OLS & Cluster-robust OLS & $\begin{array}{l}\text { Multi-level mixed- } \\
\text { effects RML }\end{array}$ & Random-effects panel ML & $\begin{array}{l}\text { Population- } \\
\text { averaged panel } \\
\text { GEE }\end{array}$ \\
\hline Model & {$[6]$} & [7] & [8] & [9] & [10] \\
\hline SE & $-35.4277^{* * *}(6.747)$ & $-35.4277^{* *}(14.107)$ & $2.2418(7.122)$ & $2.2418(10.274)$ & $-16.4359^{* * *}(6.397)$ \\
\hline $1 / S E\left(H_{0}: \gamma_{1}=0\right)$ & $-0.0885^{* * *}(0.006)$ & $-0.0885^{* * *}(0.012)$ & $-0.0797^{* * *}(0.012)$ & $-0.0797^{* * *}(0.003)$ & $-0.0843^{* * *}(0.012)$ \\
\hline K & 1472 & 1472 & 1472 & 1472 & 1472 \\
\hline$R^{2}$ & 0.605 & 0.605 & - & - & - \\
\hline
\end{tabular}

Breusch-Pagan test: $x^{2}=1301.60, p=0.0000$

b Hausman test: $x^{2}=0.55, p=0.4598$

Figures in parentheses beneath the regression coefficients are standard errors. Except for Model [9], robust standard errors are estimated. *** and ** denote statistical significance at the $1 \%$ and $5 \%$ levels, respectively

Table 6 Summary of publication selection bias tests

\begin{tabular}{|c|c|c|c|c|}
\hline \multirow[t]{2}{*}{ Study type } & \multirow{2}{*}{$\begin{array}{l}\text { Number } \\
\text { of estimates }(K)\end{array}$} & \multicolumn{3}{|l|}{ Test results ${ }^{a}$} \\
\hline & & $\begin{array}{l}\text { Funnel asymmetry test } \\
\text { (FAT) }\left(\mathrm{H}_{0}: \gamma_{0}=0\right)\end{array}$ & $\begin{array}{l}\text { Precision-effect test } \\
(\mathrm{PET})\left(\mathrm{H}_{0}: \gamma_{1}=0\right)\end{array}$ & $\begin{array}{l}\text { Precision-effect estimate } \\
\text { with standard error (PEESE) }\left(\mathrm{H}_{0} \text { : }\right. \\
\left.\gamma_{1}=0\right)^{\mathbf{b}}\end{array}$ \\
\hline All studies (Hypothesis $\mathrm{H}_{1}$ ) & 1472 & Rejected & Rejected & Rejected $(-0.0885 /-0.0797)$ \\
\hline \multicolumn{5}{|l|}{ Target region (Hypothesis $\mathrm{H}_{2}$ ) } \\
\hline Urban region & 919 & Rejected & Rejected & Rejected $(-0.0838 /-0.0788)$ \\
\hline Rural region & 135 & Rejected & Rejected & Rejected (-0.1464/-0.1436) \\
\hline Region unspecified & 418 & Rejected & Rejected & Rejected $(-0.0963 /-0.0774)$ \\
\hline \multicolumn{5}{|c|}{ Target corporate sector (Hypothesis $\mathrm{H}_{3}$ ) } \\
\hline Public sector & 24 & Not rejected & Rejected & Rejected (-0.0778/- 0.0715) \\
\hline Private sector & 34 & Not rejected & Rejected & Rejected $(-0.1293 /-0.1232)$ \\
\hline Corporate sector unspecified & 1414 & Rejected & Rejected & Rejected $(-0.0873 /-0.0715)$ \\
\hline \multicolumn{5}{|l|}{ Target period (Hypothesis $\mathrm{H}_{4}$ ) } \\
\hline 1990s or before & 315 & Not rejected & Rejected & Rejected $(-0.0861 /-0.0706)$ \\
\hline $2000 s$ & 689 & Rejected & Rejected & Rejected (- 0.0827/-0.0733) \\
\hline $2010 s$ & 468 & Not rejected & Rejected & Rejected $(-0.1349 /-0.0922)$ \\
\hline
\end{tabular}

to be small, it is highly likely to be at a medium level in rural regions and POEs. These findings are noteworthy if we are to grasp a real picture of the Chinese wage system.
Third, our results strongly suggest the possibility that the gender wage gap in China has increased dramatically in the last two decades. In fact, according to the 
publication-selection-bias-adjusted effect size generated by the PEESE method, there is a difference of approximately 1.5 times or more in the gender wage gap from the 2000s to the 2010s. This means that the gender wage gap in China already has increased to levels similar to those in developed countries in recent years. In light of the test results of hypothesis $\mathrm{H}_{3}$, we conjecture that the late expansion of the gender wage gap is closely related to the rapid development of the private sector under the background of high economic growth in China. As mentioned in Sect. 2, it is also probable that the policies for promoting the management autonomy of SOEs spurred this trend as well.

The reasons for the above findings obtained from meta-analysis in this paper can be considered to be as follows: The Chinese government promoted the economic transition from a planned system to a marketoriented economy, which caused great changes in the employment situation of many females (Meng 2000; Gustafsson and Li 2000; Maurer-Fazio and Hughes 2002; Meng 2000; Démurger et al. 2012; Li and Song 2013; Ma 2018a, c). In addition, in China, due to insufficient separation between the political and economic systems, the labor market is segmented into public and private sectors with the progress of market-oriented reforms (Liu et al. 2000; Ma 2018a, c). Moreover, remarkable imbalances remain between coastal and inland regions and between urban and rural areas (Meng 2000; Ma 2018b). As a result, the gender wage gap increased significantly during the transition period; from this viewpoint, notable disparities exist among regions and corporate sectors, which could shake the socialist system to its core. Furthermore, since China faces rapid population aging comparable to that in developed countries, promoting female labor participation is an important issue for maintaining the work force in the future. The increasing gender wage gap could be a major impediment to achieving this goal. In order to maintain sustainable growth and the development of the Chinese economy from a long-term perspective, the Chinese government should implement appropriate policies to reduce discrimination against women in the workplace.

\section{Supplementary information}

Supplementary information accompanies this paper at https://doi. org/10.1186/s12651-020-00279-5.

Additional file 1: Appendix 1. List of literature subject to meta-analysis.

Acknowledgements

This research work was financially supported by grants-in-aid for scientific research from the Ministry of Education, Culture, Sports, Science and Technology of Japan (Grant Nos. b151403m; 20H01489; 20H01512), the Joint Usage and Research Center of the Institute of Economic Research, Hitotsubashi University (Grant No. IERPK2013), and the Joint Usage and Research Center of the Institute of Economic Research, Kyoto University. We also thank Boris Hirsch (the Editor) and two anonymous reviewers for their helpful comments and suggestions, Michie Kano and Eriko Yoshida for their research assistance, and Tammy Bicket for her editorial assistance. Finally, we wish to express our deepest respect to the authors of the literature subject to the meta-analysis in this paper. Needless to say, all remaining errors are solely our responsibility.

Authors' contributions

Joint work. Both authors read and approved the final manuscript.

Funding

All sources of funding for the research are reported in the acknowledgements.

Availability of data and materials

Data available upon request

Competing interests

The authors declare that they have no competing interests.

\section{Author details}

${ }^{1}$ Institute of Economic Research, Hitotsubashi University, Naka 2-1, Kunitachi, Tokyo 186-8603, Japan. ${ }^{2}$ Center for Far Eastern Studies, University of Toyama, 3190 Gofuku, Toyama 930-8555, Japan.

\section{Appendices \\ Appendix 1}

List of literature subject to meta-analysis by language (see Additional file 1).

\section{Appendix 2}

This appendix describes the methodology of the testing for publication selection bias that we employed in Sect. 6 of this paper.

A funnel plot is a scatter plot with the effect size (in the case of this paper, the PCC) on the horizontal axis and the precision of the estimate (in this case, inverse of the standard error $1 / S E$ ) on the vertical axis. In the absence of publication selection bias, effect sizes reported by independent studies vary randomly and symmetrically around the true effect. Moreover, according to the statistical theory, the dispersion of effect sizes is negatively correlated with the precision of the estimate. Therefore, the shape of the plot must look like an inverted funnel. In other words, if the funnel plot is not bilaterally symmetrical but is deflected to one side, then an arbitrary manipulation of the study area in question is suspected, in the sense that estimates in favor of a specific conclusion (i.e., estimates with an expected sign) are more frequently published.

The FAT-PET-PEESE procedure has been developed to test publication selection bias and presence of genuine evidence in a more rigid manner: FAT can be performed by regressing the $t$ value of the $k$-th estimate on the inverse of the standard error $(1 / S E)$ using the next Eq. (1a), thereby testing the null hypothesis that the intercept term $\gamma_{0}$ is equal to zero: 


$$
t_{k}=\gamma_{0}+\gamma_{1}\left(1 / S E_{k}\right)+v_{k}
$$

where $v_{k}$ is the error term. When the intercept term $\gamma_{0}$ is statistically significantly different from zero, we can interpret that the distribution of the effect sizes is asymmetric.

Even if there is publication selection bias, a genuine effect may exist in the available empirical evidence. Stanley and Doucouliagos (2012) proposed examining this possibility by testing the null hypothesis that the coefficient $\gamma_{1}$ is equal to zero in Eq. (1a). The rejection of the null hypothesis implies the presence of genuine empirical evidence. $\gamma_{1}$ is the coefficient of precision; therefore it is called a PET.

Moreover, Stanley and Doucouliagos (2012) also stated that an estimate of the publication-selection-adjusted effect size can be obtained by estimating the following Eq. (2a), which has no intercept. If the null hypothesis of $\gamma_{1}=0$ is rejected, then the non-zero true effect does actually exist in the literature, and the coefficient $\gamma_{1}$ can be regarded as its estimate.

$$
t_{k}=\gamma_{0} S E_{k}+\gamma_{1}\left(1 / S E_{k}\right)+v_{k}
$$

This is the PEESE approach. We can see that the coefficient $\gamma_{1}$ in Eq. (2a) may become the estimate of the publication-bias-adjusted effect size in light of the fact that the following equation is obtained when both sides of Eq. (2a) are multiplied by the standard error:

$$
\text { Effect } \operatorname{size}_{k}=\gamma_{0} S E_{k}^{2}+\gamma_{1}+w_{k}
$$

When directly estimating Eq. (2b), the WLS method, with $1 / S E_{k}^{2}$ as the analytical weight, is used.

To test the robustness of the regression coefficients obtained from the above FAT-PET-PEESE procedure, we estimate Eqs. (1a) and (2a) using not only the OLS estimator, but also the cluster-robust OLS estimator, the multi-level mixed-effects RML estimator, and the unbalanced panel estimator for a robustness check.

Received: 13 January 2020 Accepted: 10 October 2020

Published online: 14 December 2020

\section{References}

Ahmed, S., McGillivray, M.: Human capital, discrimination, and the gender wage gap in Bangladesh. World Dev. 27, 506-524 (2015)

Becker, G.S.: The Economics of Discrimination. University of Chicago Press, Chicago (1957)

Becker, G.S.: Human Capital: A Theoretical and Empirical Analysis, with Special Reference to Education, 1st edn. Columbia University Press, New York (1964)

Blau, F.D., Kahn, L.M.: The gender wage gap: Extent, trends, and explanations. J. Econ. Lit. 55(3), 789-865 (2017)

Brainerd, E.: Women in transition: Changes in gender wage differentials in Eastern Europe and the Former Soviet Union. Ind. Labor Relat. Rev. 54(19), 138-162 (2000)
Chen, Yi., Démurger, S., Fournier, M.: Wage differentials and ownership structure of China's enterprise. Econ. Dev. Cult. Change 53(4), 933-958 (2005)

Cheng, T.: The determinants of gender role consciousness of Chinese women in rural regions: An empirical study based on Chinese General Survey. J Chin. Women's Stud. 103(1), 17-22 (2011) (In Chinese)

Churchill, S.A., Mishra, V.: Returns to education in China: A meta-analysis. Appl. Econ. 50(54), 5903-5919 (2018)

Cohen, J.: Statistical Power Analysis for the Behavioral Sciences, 2nd edn. Lawrence Erlbaum Associates, Hillsdale (1988)

de la Sara, R., Dolado, J.J., Llorens, V.: Ceilings or floors? Gender wage gaps by education in Spain. J. Popul. Econ. 21(3), 751-776 (2008)

Démurger, S., Li, S., Yang, J.: Earning differentials between the public and private sectors in China: Exploring changes for urban local residents in the 2002s. China Econ. Rev. 23(1), 138-153 (2012)

Deshpande, A., Goel, D., Khanna, S.: Bad Karma or discrimination? Malefemale wage gaps among workers in India. World Dev. 102, 331-344 (2018)

Dong, X., Bowles, P.: Segmentation and discrimination in China's emerging industrial labor market. China Econ. Rev. 13(2-3), 170-196 (2002)

Doucouliagos, H.: How large is large? Preliminary and relative guidelines for interpreting partial correlations in economics. School Working Paper No. SWP 2011/5, School of Accounting, Economics and Finance, Faculty of Business and Law, Deakin University, Melbourne (2011)

Fan, H., He, S., Kwan, Y.K.: FDI backward spillovers in China: What a meta-analysis tells us? Emerg. Mark. Finance Trade 56(1), 86-105 (2020)

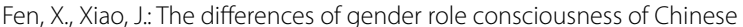
women between the rural regions and urban regions. J. Human 2014(11) (2014) (In Chinese)

Gustafsson, B., Li, S.: Economic transformation and the gender earnings gap in urban China. J. Popul. Econ. 13(2), 305-329 (2000)

Gu, J., Jixing, L., Shikui, L., Deqi, Xu.: Analysis of Contemporary Chinese Interest Group. Heilongjiang Education Press, Beijing (1995) (In Chinese)

Hallward-Driemeier, M., Rijkers, B., Waxman, A.: Can minimum wages close the gender wage gap? Evidence from Indonesia. Rev. Income Wealth $\mathbf{6 3}(2)$, 310-334 (2017)

Hara, H.: The gender wage gap across the wage distribution in Japan: Withinand between-establishment effects. Labor Econ. 53, 213-229 (2018)

Hare, D.: Decomposing growth in the gender wage gap in urban China: 1989-2011. Econ. Transit. Inst. Change 27(4), 915-941 (2019)

Iwasaki, I.: Meta-analysis of emerging markets and economies: An introductory note for the special issue. Emerg. Mark. Finance Trade 56(1), 1-9 (2020a)

Iwasaki, I.: The Economics of Transition: Developing and Reforming Emerging Economies. Routledge, Abingdon (2020b)

Iwasaki, I., Ma, X., Mizobata, S.: Corporate ownership and managerial turnover in China and Eastern Europe: A comparative meta-analysis. J Econ Bus. 111, 105928 (2020)

Japanese Institute of Labor Policy and Training (JILPT): Data Book International Comparison of Labor 2017. JILPT press, Tokyo (2017) (In Japanese)

Jarrell, S.B., Stanley, T.D.: Declining bias and gender wage discrimination? A meta-regression analysis. J. Human Res. 39(3), 828-838 (2004)

Kettle, D.F.: Earning trust in government. J. Public Aff. Educ. 24(3), 295-299 (2018)

Knight, J., Song, L.: The determinants of urban income inequity in China. Oxford Bull. Econ. Stat. 53(2), 123-154 (1991)

Li, S., Song, J.: The change of gender wage gap in of local urban workers, in change of income inequality in China. In: Li, Shi, Hiroshi Sato and Terry Sicular (eds.), Studies of Chinese Household Income IV. Chinese People's Publishing House (2013) (In Chinese)

Li, S., Yue, X., Sicular, T., Sato, H.: The New Change of Income Distribution in China: Studies of Chinese Household Income V. China Financial and Economic Publishing House, China (2017) (In Chinese)

Liu, D.: Income disparity and social instability in China. In: Falkus, M., Kim, K.S., Mimani, R. (eds.) Growth, Distribution and Political Change: Asia and the Wider World, pp. 91-113. Palgrave Macmillan, Basingstoke (1999)

Liu, P.-W., Meng, X., Zhang, J.: Sectoral gender wage differentials and discrimination in the transitional Chinese economy. J. Popul. Econ. 13(2), 331-352 (2000)

Liu, Y.: Sociological thinking on the current prominent phenomenon of positively participation to the examination of civil servants. Reading Writing 2015(7) (2015) (In Chinese) 
Ljungwall, C., Tingvall, P.G.: Is China different? A meta-analysis of the growthenhancing effect from R\&D spending in China. China Econ. Rev. 36, 272-278 (2015)

Ma, X:: Ownership sector segmentation and the gender wage gap in urban China during the 2000s. Post-Commun. Econ. 30(6), 775-804 (2018a)

$\mathrm{Ma}, \mathrm{X}$.: Labor market segmentation by industry sectors and wage gaps between migrants and local urban residents in urban China. China Econ. Rev. 47, 96-115 (2018b)

Ma, X.: Economic Transition and Labor Market Reform in China. Palgrave Macmillan, Singapore (2018c)

Ma, X., Iwasaki, I.: Does party membership bring a wage premium in China? A meta-analysis. J. Chin. Econ. Bus. Stud (2020) (In press)

Majchrowska, A., Strawiński, P.: Impact of minimum wage increase on gender wage gap: Case of Poland. Econ. Model. 70, 174-185 (2018)

Maurer-Fazio, M., Hughes, J.: The effects of market liberalization on the relative earnings of Chinese women. J. Comp. Econ. 30(4), 709-731 (2002)

Meng, X.: Male-female wage determination and gender wage discrimination in China' rural industrial sector. Labor Econ. 5(1), 67-89 (1998a)

Meng, X.: Gender occupational segregation and its impact on the gender wage differential among rural-urban migrants: A Chinese case study. Appl. Econ. 30(6), 741-752 (1998b)

Meng, X.: Labor Market Reform in China. Cambridge University Press, Cambridge (2000)

Meng, X., Miller, P.: Occupational segregation and its impact on gender wage discrimination in China' rural industrial sector. Oxford Econ. Paper 47(1), 136-155 (1995)

Minami, R., Ma, X.: The Lewisian turning point of Chinese economy: Comparison with Japanese experience. Chin. Econ. J. 3(2), 165-181 (2010)

Mincer, J.: Schooling, Experience and Earning. Columbia University Press, New York (1974)

Nakagawa, S., Noble, D.W.A., Senior, A.M., Lagisz, M.: Meta-evaluation of metaanalysis: Ten appraisal questions for biologists. BMC Biol (2017). https:// doi.org/10.1186/s12915-017-0357-7

National Bureau of Statistics of China: China Statistical Yearbook 2018. China Statistics Press, China (2018) (In Chinese)

Ren, W., Miller, P.W.: Gender differentials in the payoff to schooling in rural China. J. Dev. Stud. 48(1), 133-150 (2012)

Rozelle, S., Dong, X., Zhang, L., Mason, A.: Gender wage gaps in post-reform rural China. Pacific Econ. Rev. 7(1), 157-179 (2002)
Shu, X., Zhu, Y., Zhang, Z.: Global economy and gender inequalities: The case of the urban Chinese labor market. Soc. Sci. Q. 88(5), 1307-1332 (2007)

Song, J., Siclar, T., Gustafson, B.: The gender wage gap of urban workers: A new trend. In: Li, Shi, Ximing Yue, Terry Sicular and Hiroshi Sato (eds.), The New Change of Income Distribution in China-Studies of Chinese Household Income V. China Financial and Economic Publishing House (2017) (In Chinese)

Song, S., Zhu, E., Chen, Z.: Equal work opportunity but unequal income: Gender disparities among low-income households in urban China. Chin. Econ. 44(1), 39-45 (2011)

Stanley, T.D., Doucouliagos, H.: Meta-Regression Analysis in Economics and Business. Routledge, London (2012)

Stanley, T.D., Doucouliagos, H.: Neither fixed nor random: Weighted least squares meta-regression. Res. Syn. Method 8(1), 19-42 (2017)

Stanley, T.D., Jarrell, S.B.: Gender wage discrimination bias? A meta-regression analysis. J. Human Res. 33(4), 947-973 (1998)

Stanley, T.D., Doucouliagos, H., loannidis, J.P.A.: Finding the power to reduce publication bias. Stat. Med. 36(10), 1580-1598 (2017)

Sun, Qi., Hung, J.H.: The rise in China's gender income inequality. In: Hung, J.H., Chen, Y. (eds.) The State of China's State Capitalism, pp. 219-236. Springer, Singapore (2018)

Weichselbaumer, D., Winter-Ebmer, R.: A meta-analysis of the international gender wage gap. J. Econ. Surv. 19(3), 479-511 (2005)

Zhang, J., Zhao, W.: Current situation of income distribution in China and thoughts of reduction of gap: Measures to be taken by the government to maintain the social stability. Nikkei Business https://business.nikke i.com (2018). Accessed 20 Jul 2018 (In Japanese)

Zhao, X.-Z., Zhao, Y.-B., Chou, L.-C., Leivang, B.H.: Changes in gender wage differentials in China: A regression and decomposition based on the data of CHIPS1995-2013. Econ. Res.-Ekonomska Istraživanja 32(1), 3162-3182 (2019)

\section{Publisher's Note}

Springer Nature remains neutral with regard to jurisdictional claims in published maps and institutional affiliations.

\section{Submit your manuscript to a SpringerOpen ${ }^{\circ}$ journal and benefit from:}

- Convenient online submission

- Rigorous peer review

- Open access: articles freely available online

- High visibility within the field

- Retaining the copyright to your article

Submit your next manuscript at springeropen.com 